\title{
Product Authentication Using Two Mitochondrial Markers Reveals Inconsistent Labeling and Substitution of Canned Tuna Products in the Taiwanese Market
}

\author{
Chia-Hao Chang ${ }^{1}\left(\mathbb{D}\right.$, Yueh-Tzu Kao ${ }^{2}$, Ting-Ting Huang ${ }^{1}$ and Yu-Chun Wang ${ }^{3, *}$ \\ 1 TIGP Biodiversity Program, Tunghai University, No.1727, Sec.4, Taiwan Boulevard, Xitun District, \\ Taichung City 407224, Taiwan; chiahao0928@gmail.com (C.-H.C.); miaotingting00@gmail.com (T.-T.H.) \\ 2 Department of Life Science, Tunghai University, No.1727, Sec.4, Taiwan Boulevard, Xitun District, \\ Taichung City 407224, Taiwan; hyakkiin@gmail.com \\ 3 Planning and Information Division, Fisheries Research Institute, No.199, Hou-Ih Road, \\ Keelung City 202008, Taiwan \\ * Correspondence: ycwang@mail.tfrin.gov.tw; Tel.: +886-2-24622101 (ext. 2524)
}

\section{check for}

updates

Citation: Chang, C.-H.; Kao, Y.-T.; Huang, T.-T.; Wang, Y.-C. Product Authentication Using Two Mitochondrial Markers Reveals Inconsistent Labeling and Substitution of Canned Tuna Products in the Taiwanese Market. Foods 2021, 10, 2655. https:// doi.org/10.3390/foods10112655

Academic Editor: Pedro Vitoriano de Oliveira

Received: 7 September 2021

Accepted: 28 October 2021

Published: 2 November 2021

Publisher's Note: MDPI stays neutral with regard to jurisdictional claims in published maps and institutional affiliations.

Copyright: (c) 2021 by the authors. Licensee MDPI, Basel, Switzerland. This article is an open access article distributed under the terms and conditions of the Creative Commons Attribution (CC BY) license (https:// creativecommons.org/licenses/by/ $4.0 /)$

\begin{abstract}
Fish of the tribe Thunnini represent a significant proportion of the stock caught by the fishing industry, with many of these fishes being collectively called tuna. However, only certain species can be used legally as an ingredient in canned tuna products, depending on regional food regulations. In Taiwan, only Thunnus species or Katsuwonus pelamis can be used as canned tuna. Here, we authenticated 90 canned tuna products, including 25 cat food samples, by sequencing two mitochondrial regions, 16S rRNA (16S) and the control region (CR). BLAST analysis revealed that Sarda orientalis, Euthynnus affinis, Auxis rochei, and Auxis thazard are all used as substitutes for legitimate tuna products. We found that $63.33 \%$ of investigated samples are true canned tuna, i.e., contain Thunnus species or skipjack tuna. We advocate that the Taiwanese government publishes an official standardized list of fishes, especially so that scientific, Chinese and vernacular names can be assigned unambiguously based on a "one species-one name policy", thereby clarifying which species can be used in seafood products such as tuna. Furthermore, we feel that the large-scale and long-term monitoring of canned tuna products is warranted to fully assess the extent of tuna product adulteration in Taiwan.
\end{abstract}

Keywords: Thunnini; substitution; mislabeling rate; one species-one name; adulteration

\section{Introduction}

Approximately 17\% of the global human population's intake of animal protein in 2017 constituted fish [1]. Although aquaculture satisfied about half of that consumption, wild-capture from oceans, lakes and rivers remains a mainstay of the global fishing industry. Among these wild-caught fishes, scombrids are particularly important fishery resources, especially species in the tribe Thunnini that constitute $\sim 10 \%$ of the international seafood market [2,3]. In 2018, the global catch of Thunnini species represented 7.9 million tons, $58 \%$ of which can be attributed to skipjack tuna (Katsuwonus pelamis) (in Chinese: 正鰹) and yellowfin tuna (Thunnus albacares) (in Chinese: 黃鯺鮁) [1]. A large proportion of the Thunnini catch is destined for the canning industry $[4,5]$.

The tribe Thunnini comprises five genera: Thunnus (in Chinese: 鮁屬), Katsuwonus (in Chinese: 正鰹屬), Auxis (in Chinese: 花鰹屬), Euthynnus (in Chinese: 巴鰹屬), and Allothunnus (in Chinese: 細鰹屬). Fishes of this tribe can be generally termed “tuna”. For example, Auxis rochei is called bullet tuna (in Chinese: 圆花鰹), Euthynnus alleteratus is little tunny (in Chinese: 小巴䚚), and Allothunnus fallai is slender tuna (in Chinese: 細㙰). However, the Chinese translation of tuna is 鮁 in Taiwan or 金槍魚 in Mainland China, which specifically refers solely to Thunnus spp. Previously, many different scombrids were used as an ingredient in "canned tuna", even if they did not belong to the tribe Thunnini. 
For instance, Sarda (in Chinese: 苜䱧屬) spp. were once widely used in canned tuna because they possess a similar taste and texture to it [6]. Importantly, a species of the tribe Thunnini may not always be used legally as a canned tuna product ingredient. Various legislative bodies have developed regulations that clearly define which species can be used in canned tuna products (Table 1). The Food and Agriculture Organization (FAO) and the federal government of the United States allow spotted tuna to be used as canned tuna, but that species is prohibited by Taiwanese and Japanese regulations. In general, fishes of the genus Thunnus and skipjack tuna are widely recognized as legal canned tuna species. To align with international standards, the Taiwan Food and Drug Administration allows skipjack tuna to be used in 鮁 (for tuna)-labeled canned tuna products, even though it does not belong to the genus Thunnus, but other "pseudo-tunas" can no longer be used legally as a canned tuna ingredient.

Table 1. Scientific, English common, Chinese common and vernacular names of scombrid fishes permitted by various legislative bodies as canned tuna or bonito products.

\begin{tabular}{|c|c|c|c|c|c|c|c|c|}
\hline Scientific Name & $\begin{array}{c}\text { English } \\
\text { Common Name }\end{array}$ & $\begin{array}{l}\text { Chinese } \\
\text { Name }\end{array}$ & $\begin{array}{c}\text { Chinese Vernacular } \\
\text { Name }\end{array}$ & Taiwan $^{1}$ & $\mathrm{FAO}^{2}$ & USA $^{3}$ & Japan $^{4}$ & $\begin{array}{c}\text { European } \\
\text { Union } 5\end{array}$ \\
\hline \multicolumn{9}{|l|}{ Thunnini tribe } \\
\hline Thunnus alalunga & Albacore tuna & 長鰭鮁 & 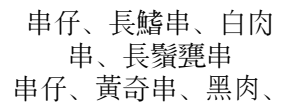 & $\boldsymbol{v}$ & $\checkmark$ & $\checkmark$ & $\checkmark$ & $\checkmark$ \\
\hline Thunnus albacares & Yellowfin tuna & 黃鰭鮁 & 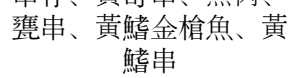 & $\checkmark$ & $\checkmark$ & $\checkmark$ & $\checkmark$ & $\checkmark$ \\
\hline $\begin{array}{l}\text { Thunnus } \\
\text { atlanticus }\end{array}$ & Blackfin tuna & 黑鯺鮁 & & $\checkmark$ & $\checkmark$ & $\boldsymbol{V}$ & & $\checkmark$ \\
\hline Thunnus obesus & Bigeye tuna & 大目鮁 & $\begin{array}{l}\text { 大目仔、大眼鮁、大目 } \\
\text { 串、短墩、串仔、短鮁 }\end{array}$ & $\checkmark$ & $\checkmark$ & $\checkmark$ & $\checkmark$ & $\checkmark$ \\
\hline Thunnus maccoyii & $\begin{array}{l}\text { Southern bluefin } \\
\text { tuna }\end{array}$ & 南方黑鮁 & & $\boldsymbol{V}$ & $\checkmark$ & $\checkmark$ & & $\checkmark$ \\
\hline Thunnus thynnus & $\begin{array}{l}\text { Atlantic bluefin } \\
\text { tuna }\end{array}$ & 大西洋黑鮁 & & $\checkmark$ & $\checkmark$ & $\checkmark$ & & $\checkmark$ \\
\hline Thunnus orientalis & $\begin{array}{l}\text { Pacific bluefin } \\
\text { tuna }\end{array}$ & 太平洋黑鮁 & 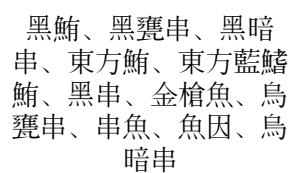 & $\boldsymbol{v}$ & $\checkmark$ & $\checkmark$ & $\checkmark$ & $\checkmark$ \\
\hline Thunnus tonggol & Longtail tuna & 長腰鮁 & $\begin{array}{l}\text { 黑鮱串、串仔、長實、 } \\
\text { 長翼、小黃鮱鮁 } \\
\text { 煙仔虎、煙仔、小串、 }\end{array}$ & $\boldsymbol{v}$ & $\checkmark$ & $\checkmark$ & $\checkmark$ & $\checkmark$ \\
\hline $\begin{array}{l}\text { Katsuwonus } \\
\text { pelamis }\end{array}$ & Skipjack tuna & 正鰹 & $\begin{array}{c}\text { 柴魚、肥煙、鯤、煙仔 } \\
\text { 魚、卓鰾、大煙 }\end{array}$ & $\checkmark$ & $\checkmark$ & $\checkmark$ & $\checkmark$ & $\checkmark$ \\
\hline Auxis rochei & Bullet tuna & 圓花鰹 & $\begin{array}{c}\text { 煙管仔、竹棍魚、槍管 } \\
\text { 煙、鎗管煙子 } \\
\text { 煙仔魚、油煙、花煙、 }\end{array}$ & & & $\checkmark$ & & \\
\hline Auxis thazard & Frigate tuna & 扁花鰹 & $\begin{array}{c}\text { 平花鰹、憼煙、平花 } \\
\text { 煙、腩煙 } \\
\text { 三點仔、煙仔、倒串、 }\end{array}$ & & & $\checkmark$ & & \\
\hline Euthynnus affinis & Kawakawa & 巴鰹 & 鯤、花煙、大鯰煙、花 & & $\checkmark$ & $\checkmark$ & & \\
\hline $\begin{array}{l}\text { Euthynnus } \\
\text { alleteratus }\end{array}$ & Little tunny & 小巴鰹 & & & $\checkmark$ & $\checkmark$ & & \\
\hline $\begin{array}{l}\text { Euthynnus } \\
\text { lineatus }\end{array}$ & $\begin{array}{l}\text { Black skipjack } \\
\text { tuna }\end{array}$ & 黑巴鰹 & & & $\checkmark$ & $\checkmark$ & & \\
\hline $\begin{array}{l}\text { Allothunnus fallai } \\
\text { Sardini tribe }\end{array}$ & Slender tuna & 細䚛 & & & & $\checkmark$ & & \\
\hline Sarda orientalis & Oriental bonito & 東方菌鰆 & 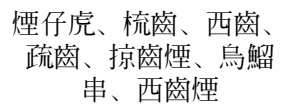 & & $\checkmark$ & & & \\
\hline Sarda sarda & Atlantic bonito & 菌鰆 & & & $\checkmark$ & & & \\
\hline Sarda chilensis & $\begin{array}{l}\text { Eastern Pacific } \\
\quad \text { bonito }\end{array}$ & 智利菌鰆 & & & $\checkmark$ & & & \\
\hline
\end{tabular}

${ }^{1}$ 107年度『建構完整食品標示管理體系計畫』—『宣粫鮊魚罐頭之標示説明會』，Taiwan; ${ }^{2}$ Standard for canned tuna and bonito CXS 70-1981, Codex Alimentarius FAO-WHO; ${ }^{3}$ Code of federal regulations CFR 21. Sec. 161.190. United State Food and Drug Administration, USA; ${ }^{4}$ 水産物缶詰及び水産物瓶詰の日本農林規格, Japan; ${ }^{5}$ European regulation (Council Regulation (EEC) No 1536/92) [7-11]. 
Seafood mislabeling is profuse worldwide [12-21]. Such mislabeling can be categorized into two types, i.e., deliberate or unintentional. Deliberate mislabeling primarily involves the substitution of high-priced fishes with low-priced ones for financial reasons, though the reverse scenario also arises occasionally, perhaps due to illegal fishing. Unintentional mislabeling occurs when morphologically similar fishes are misidentified, when the usage of vernacular names is not unified, or when product information is lost along the supply chain. Whatever the form of mislabeling, it ultimately entails consumer deception, public health risk, problems for fisheries management, and has religious implications (reviewed in Chang et al. [22]).

Traditional morphology-based identification is rarely applied to seafood because many products undergo physical (e.g., filleting) or chemical (e.g., smoking) processing before being sold. These aspects of food processing typically eliminate diagnostic morphological characters needed for species authentication. Fortunately, molecular authentication based on nucleic acid sequence similarity can overcome this limitation. DNA can be obtained from a tiny piece of tissue and it is more resistant to degradation and food processing. Therefore, DNA-based authentication is being widely employed to identify species in seafood [15,21,23-30].

The increasing global popularity of Japanese cuisine has markedly increased market demand for tuna, since Thunnus fishes are important elements of sashimi and sushi. The development of freezing technology and booming global trade in the early 1970s has transformed the bluefin tunas (T. thynnus (in Chinese: 大西洋黑鮊), T. maccoyii (in Chinese: 南方黑鮊), and T. orientalis (in Chinese: 太平洋黑鮹)) from a cat food into a delicacy served at high-end restaurants [31]. Bluefin tunas are the most sought after of all Thunnus fishes, attaining the largest size and greatest price. However, increased consumption has also threatened their stocks, which are decreasing and the status of all three species is deemed Critical (IUCN). Today, regional fishery management organizations are responsible for managing and monitoring tuna fishing in order to keep it sustainable [32].

The soaring demand for Thunnus fishes, especially bluefin tuna, makes them very vulnerable to mislabeling. Previous molecular authentication studies on sushi reported that many fishes are used as substitutes for Thunnus species, including escolar (Lepidocybium flavobrunneum) (in Chinese: 鱗網帶鰆), salmon (Salmo salar) (in Chinese: 安 大略鱒), banded rudderfish (Seriola zonata) (in Chinese: 環帶鯔), great amberjack (Seriola dumerili) (in Chinese: 杜氏鰤), skipjack tuna, little tunny, as well as various shark species $[14,17,18,20,33-37]$. Furthermore, the value of different Thunnus species varies, prompting high-priced bluefin tuna or bigeye tuna (T. obesus) (in Chinese: 大目鮹) to be substituted for a cheaper species such as yellowfin tuna. Notably, enforcement of fishery management can drive reverse substitution, whereby high-priced bluefin tuna is sold as cheap yellowfin tuna or Thunnus fishes are labeled as skipjack tuna to enable market entry of illegal catch $[33,38,39]$.

Although DNA-based methods are very powerful tools for authenticating fish products, food processing, and especially canning, can limit their applicability. To date, conventional DNA barcoding remains the most widely deployed authentication approach, whereby a $\sim 650$-bp region of the mitochondrial gene encoding for cytochrome c subunit I (COI) is sequenced as a bioidentification "barcode" [40,41]. However, the high heat treatment integral to the canning process largely degrades DNA into small fragments [42,43], so shorter fragments (or nested polymerase chain reaction, PCR) must be deployed for canned products $[4-6,39,44,45]$, but a comprehensive investigation of canned tuna substitution in a particular region has not yet been conducted. In Taiwan, the mislabeling rate of tuna products varies according to the product type. Chang et al. [22] documented that all tuna-labeled meals produced at conveyor-belt sushi restaurants appear to truly come from Thunnus fishes, but Xiong et al. [46] and Hwang et al. [44] detected mislabeled Taiwan canned tuna products. Therefore, the goal of this study is to estimate levels of canned tuna product adulteration and to determine which species of scombrids are being marketed as canned product in the Taiwanese market. 


\section{Materials and Methods}

\subsection{Sample Collection}

We purchased a total of 90 canned tuna products, belonging to 59 brands, from grocery stores or online, encompassing all major brands in Taiwan. Twenty-five of the collected samples represented canned cat food. Cans were selected if their label showed the Chinese word 鮁 (for tuna), if the company website claimed the product was made from Thunnus fishes, if the ingredients list contained Thunnus spp. or skipjack tuna, or if an image on the label indicated the can harbored Thunnus fishes. We recorded information, typically written in Chinese, on brand, manufacturer or importer, place of manufacture, labeling, and ingredients. If the cans were imported from the USA or Japan, the respective English or Japanese labels were also recorded (Table 2). The sampled cans were first photographed using a smartphone (Supplementary Information S1), and then a small quantity of the contents of each can was removed using autoclaved dissection tools, washed with $95 \%$ ethanol, before being preserved in $99.5 \%$ ethanol at $-20{ }^{\circ} \mathrm{C}$ until DNA extraction. Some of the canned cat food products contained more than one type of meat, so potential Thunnus meat was selected based on color and texture.

\subsection{Molecular Identification}

DNA was extracted from each of the 90 tissue samples using DNA Extraction Kit S (Cat No./ID: GS100, Geneaid). PCR amplifications of the mitochondrial $16 \mathrm{~S}$ rRNA fragment $(16 \mathrm{~S})(85 \mathrm{bp})$ were performed in a mixture containing $5 \mathrm{ng}$ template DNA, $12.5 \mu \mathrm{L}$ of $2 \times$ Taq PCR MasterMix (GN-PCR201-01, Genomix), and $12.5 \mu \mathrm{mol}$ of each forward and reverse primer. We used primers designed by Horreo et al. [47] and modified them by adding M13 primer to facilitate sequencing: Forward, M13F(-20)16S-HF (5'-GTA AAA CGA CGG CCA GTA TAA CAC GAG AAG ACC CT-3'); Reverse, M13R(-24)16S-HR1+2 (5'-AACAGCTATGACCATGCCCRCGGTCGCCCCA AC- $\left.3^{\prime}\right)$. These primers were made up to a final volume of $25 \mu \mathrm{L}$ using distilled water. If BLAST analysis (in the NCBI basic local alignment search tool) indicated that a sequenced $16 \mathrm{~S}$ fragment belonged to Thunnus spp., we PCR-amplified a fragment of the mitochondrial control region (CR, approximately $236 \mathrm{bp}$ ) from the same DNA sample. CR amplification was conducted in a mixture containing $5 \mathrm{ng}$ template DNA, $12.5 \mu \mathrm{L}$ of $2 \times$ Taq PCR MasterMix (GN-PCR201-01, Genomix), and $12.5 \mu \mathrm{mol}$ of each forward and reverse primer-Forward, Tuna-CR_F; Reverse, Tuna-CR_R1 or Tuna-CR_R2 [48]—made up to a final volume of $25 \mu \mathrm{L}$ using distilled water. Thermal cycling began with one cycle at $95{ }^{\circ} \mathrm{C}$ for $4 \mathrm{~min}$, followed by 35 cycles of denaturation at $95^{\circ} \mathrm{C}$ for $30 \mathrm{~s}, 47-55^{\circ} \mathrm{C}$ for $30 \mathrm{~s}$, and $72^{\circ} \mathrm{C}$ for $30 \mathrm{~s}$ and, finally, a single extension step at $72{ }^{\circ} \mathrm{C}$ for $7 \mathrm{~min}$. PCR products were purified using a PCR DNA Fragment Extraction Kit (Geneaid, Taipei, Taiwan). The amplified mitochondrial fragments were subjected to Sanger sequencing, performed by Mission Biotech. (Taipei, Taiwan) using M13 sequencing primers. Primer sequences linked to the amplified fragments were trimmed before constructing the contigs using CodonCode Aligner. The mitochondrial sequences we generated in this study have not been submitted to GenBank as they do not come from voucher specimens. 


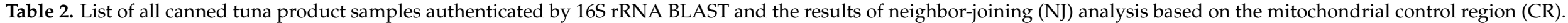

\begin{tabular}{|c|c|c|c|c|c|c|c|c|c|c|c|c|c|c|}
\hline No. & $\begin{array}{l}\text { Sample } \\
\text { Code }\end{array}$ & Brand & $\begin{array}{c}\text { Manufacturer } \\
\text { or } \\
\text { Importer }\end{array}$ & $\begin{array}{l}\text { Place of } \\
\text { Manufac- } \\
\text { ture }\end{array}$ & $\begin{array}{l}\text { Chinese } \\
\text { Label }\end{array}$ & $\begin{array}{l}\text { English } \\
\text { Label }\end{array}$ & $\begin{array}{l}\text { Declared } \\
\text { Ingredient }\end{array}$ & $\begin{array}{c}\text { English } \\
\text { Transla- } \\
\text { tion of } \\
\text { Ingredient }\end{array}$ & $\begin{array}{l}\text { Inconsistent } \\
\text { Labeling }\end{array}$ & $\begin{array}{c}16 S \text { rRNA } \\
\text { Haplotype } \\
\text { Code }\end{array}$ & $\begin{array}{c}\text { 16S BLAST } \\
\text { (No. of Hits) }\end{array}$ & $\begin{array}{l}\text { CR NJ } \\
\text { Analysis }\end{array}$ & Mislabeled & $\begin{array}{c}\text { True } \\
\text { Canned } \\
\text { Tuna }\end{array}$ \\
\hline 1 & $\mathrm{~T} 1$ & 遠洋牌 & $\begin{array}{l}\text { 興毅冷凍 } \\
\text { 食品 }\end{array}$ & Taiwan & 鮊魚片 & $\begin{array}{l}\text { Light tuna } \\
\text { in oil }\end{array}$ & 鮁魚 & $\begin{array}{l}\text { Thunnus } \\
\text { spp. }\end{array}$ & $\mathrm{NO}$ & Hap_F & $\begin{array}{c}\text { Thunnus } \\
\text { tonggol (101), T. } \\
\text { orientalis (4), T. } \\
\text { atlanticus (2), T. } \\
\text { thynnus (4), T. } \\
\text { albacares (14), T. } \\
\text { maccoyii (6), T. } \\
\text { obesus (4), T. } \\
\text { alalunga (1), } \\
\text { Katsuwonus } \\
\text { pelamis (1) }\end{array}$ & T. albacares & NO & YES \\
\hline 2 & T53 & 遠洋牌 & $\begin{array}{l}\text { 興毅冷凍 } \\
\text { 食品 }\end{array}$ & Taiwan & $\begin{array}{c}\text { 油漬鮁魚 } \\
\text { 肉塊(煙仔 } \\
\text { 虎) }\end{array}$ & & 煙仔虎 & $\begin{array}{c}\text { Skipjack } \\
\text { tuna or } \\
\text { oriental } \\
\text { bonito }\end{array}$ & YES & Hap_G & $\begin{array}{c}\text { Auxis thazard } \\
\text { (6), A. rochei (7), } \\
\text { Euthynnus } \\
\text { affinis (1) }\end{array}$ & & YES & $\mathrm{NO}$ \\
\hline 3 & T57 & 遠洋牌 & $\begin{array}{l}\text { 興毅冷凍 } \\
\text { 食品 }\end{array}$ & Taiwan & 玉米+鮁魚 & $\begin{array}{c}\text { Tuna }+ \\
\text { sweet corn }\end{array}$ & 鮁魚 & $\begin{array}{l}\text { Thunnus } \\
\text { spp. }\end{array}$ & $\mathrm{NO}$ & Hap_F & $\begin{array}{c}\text { Thunnus } \\
\text { tonggol (101), T. } \\
\text { orientalis (4), T. } \\
\text { atlanticus (2), T. } \\
\text { thynnus (4), T. } \\
\text { albacares (14), T. } \\
\text { maccoyii (6), T. } \\
\text { obesus (4), T. } \\
\text { alalunga (1), } \\
\text { Katsuwonus } \\
\text { pelamis (1) }\end{array}$ & & $\mathrm{NO}$ & YES \\
\hline 4 & T62 & 三興 & 惠罗食品 & Taiwan & $\begin{array}{l}\text { 紂SH油清 } \\
\text { 鮁魚(東方 } \\
\text { 齒鰆) }\end{array}$ & Tuna in oil & 東方萃鰆 & $\begin{array}{l}\text { Oriental } \\
\text { bonito }\end{array}$ & YES & Hap_A & $\begin{array}{l}\text { Sarda orientalis } \\
\text { (3) }\end{array}$ & & $\mathrm{NO}$ & $\mathrm{NO}$ \\
\hline 5 & $\mathrm{~T} 2$ & 三興 & 惠罗食品 & Taiwan & $\begin{array}{l}\text { SH水者鮁 } \\
\text { 魚(東方莮 } \\
\text { 鰆) }\end{array}$ & $\begin{array}{l}\text { Tuna in } \\
\text { brine }\end{array}$ & 東方萃鰆 & $\begin{array}{c}\text { Oriental } \\
\text { bonito }\end{array}$ & YES & Hap_A & $\begin{array}{c}\text { Sarda orientalis } \\
\text { (3) }\end{array}$ & & $\mathrm{NO}$ & $\mathrm{NO}$ \\
\hline
\end{tabular}


Table 2. Cont

\begin{tabular}{|c|c|c|c|c|c|c|c|c|c|c|c|c|c|c|}
\hline No. & $\begin{array}{l}\text { Sample } \\
\text { Code }\end{array}$ & Brand & $\begin{array}{c}\text { Manufacturer } \\
\text { or } \\
\text { Importer }\end{array}$ & $\begin{array}{l}\text { Place of } \\
\text { Manufac- } \\
\text { ture }\end{array}$ & $\begin{array}{c}\text { Chinese } \\
\text { Label }\end{array}$ & $\begin{array}{c}\text { English } \\
\text { Label }\end{array}$ & $\begin{array}{l}\text { Declared } \\
\text { Ingredient }\end{array}$ & $\begin{array}{c}\text { English } \\
\text { Transla- } \\
\text { tion of } \\
\text { Ingredient }\end{array}$ & $\begin{array}{l}\text { Inconsistent } \\
\text { Labeling }\end{array}$ & $\begin{array}{c}16 S \text { rRNA } \\
\text { Haplotype } \\
\text { Code }\end{array}$ & $\begin{array}{l}\text { 16S BLAST } \\
\text { (No. of Hits) }\end{array}$ & $\begin{array}{c}\text { CR NJ } \\
\text { Analysis }\end{array}$ & Mislabeled & $\begin{array}{c}\text { True } \\
\text { Canned } \\
\text { Tuna }\end{array}$ \\
\hline 6 & $\mathrm{~T} 3$ & 好媽媽 & 東和食品 & Taiwan & 纖麗鮁魚 & $\begin{array}{l}\text { Tuna flakes } \\
\text { in brine }\end{array}$ & 鮁魚 & $\begin{array}{l}\text { Thunnus } \\
\text { spp. }\end{array}$ & $\mathrm{NO}$ & Hap_C & $\begin{array}{l}\text { Katsuwonus } \\
\text { pelamis (7), } \\
\text { Thunnus } \\
\text { albacares (1) }\end{array}$ & & YES & YES \\
\hline 7 & T52 & 好媽媽 & 東和食品 & Taiwan & 辣妹鮁魚 & $\begin{array}{l}\text { Tuna flakes } \\
\text { in chili oil }\end{array}$ & 鮁魚 & $\begin{array}{l}\text { Thunnus } \\
\text { spp. }\end{array}$ & $\mathrm{NO}$ & Hap_F & $\begin{array}{c}\text { Thunnus } \\
\text { tonggol (101), T. } \\
\text { orientalis (4), T. } \\
\text { atlanticus (2), T. } \\
\text { thynnus (4), T. } \\
\text { albacares (14), T. } \\
\text { maccoyii (6), T. } \\
\text { obesus (4), T. } \\
\text { alalunga (1), } \\
\text { Katsuwonus } \\
\text { pelamis (1) }\end{array}$ & & $\mathrm{NO}$ & YES \\
\hline 8 & $\mathrm{~T} 4$ & 好媽媽 & 東和食品 & Taiwan & $\begin{array}{c}\text { 三明治鮁 } \\
\text { 魚 (煙仔虎) }\end{array}$ & $\begin{array}{c}\text { Tuna } \\
\text { sandwich }\end{array}$ & $\begin{array}{c}\text { 煙仔虎 (鮁 } \\
\text { 魚) }\end{array}$ & $\begin{array}{c}\text { Skipjact } \\
\text { tuna or } \\
\text { oriental } \\
\text { bonito } \\
\text { (Thunnus } \\
\text { spp.) }\end{array}$ & YES & Hap_A & $\begin{array}{l}\text { Sarda orientalis } \\
\text { (3) }\end{array}$ & & $?$ & $\mathrm{NO}$ \\
\hline 9 & T49 & 好媽媽 & 東和食品 & Taiwan & $\begin{array}{c}\text { 無添加玉 } \\
\text { 米鮁魚 } \\
\text { Corn Tuna }\end{array}$ & Corn tuna & 煙仔虎 & $\begin{array}{c}\text { Skipjact } \\
\text { tuna or } \\
\text { oriental } \\
\text { bonito }\end{array}$ & YES & Hap_A & $\begin{array}{c}\text { Sarda orientalis } \\
\text { (3) }\end{array}$ & & $\mathrm{NO}$ & $\mathrm{NO}$ \\
\hline 10 & $\mathrm{~T} 18$ & $\begin{array}{c}\text { 蘇澳區漁 } \\
\text { 會 }\end{array}$ & 東和食品 & Taiwan & 水煮鮁魚 & $\begin{array}{c}\text { Canned } \\
\text { boiled tuna }\end{array}$ & 鮁魚 & $\begin{array}{c}\text { Thunnus } \\
\text { spp. }\end{array}$ & $\mathrm{NO}$ & Hap_B & $\begin{array}{l}\text { Euthynnus } \\
\text { affinis (4), E. } \\
\text { lineatus (1) }\end{array}$ & & YES & $\mathrm{NO}$ \\
\hline 11 & $\mathrm{~T} 20$ & 冬山河 & 東和食品 & Taiwan & $\begin{array}{c}\text { 三明治鮁 } \\
\text { 魚 }\end{array}$ & & 鮁魚 & $\begin{array}{l}\text { Thunnus } \\
\text { spp. }\end{array}$ & $\mathrm{NO}$ & Hap_B & $\begin{array}{l}\text { Euthynnus } \\
\text { affinis (4), E. } \\
\text { lineatus (1) }\end{array}$ & & YES & $\mathrm{NO}$ \\
\hline
\end{tabular}


Table 2. Cont

\begin{tabular}{|c|c|c|c|c|c|c|c|c|c|c|c|c|c|c|}
\hline No. & $\begin{array}{l}\text { Sample } \\
\text { Code }\end{array}$ & Brand & $\begin{array}{c}\text { Manufacturer } \\
\text { or } \\
\text { Importer }\end{array}$ & $\begin{array}{l}\text { Place of } \\
\text { Manufac- } \\
\text { ture }\end{array}$ & $\begin{array}{l}\text { Chinese } \\
\text { Label }\end{array}$ & $\begin{array}{c}\text { English } \\
\text { Label }\end{array}$ & $\begin{array}{l}\text { Declared } \\
\text { Ingredient }\end{array}$ & $\begin{array}{c}\text { English } \\
\text { Transla- } \\
\text { tion of } \\
\text { Ingredient }\end{array}$ & $\begin{array}{l}\text { Inconsistent } \\
\text { Labeling }\end{array}$ & $\begin{array}{l}\text { 16S rRNA } \\
\text { Haplotype } \\
\text { Code }\end{array}$ & $\begin{array}{l}\text { 16S BLAST } \\
\text { (No. of Hits) }\end{array}$ & $\begin{array}{c}\text { CR NJ } \\
\text { Analysis }\end{array}$ & Mislabeled & $\begin{array}{c}\text { True } \\
\text { Canned } \\
\text { Tuna }\end{array}$ \\
\hline 12 & $\mathrm{~T} 21$ & 鮮拚鮮 & 東和食品 & Vietnam & 鮕魚罐頭 & & 鮁魚 & $\begin{array}{l}\text { Thunnus } \\
\text { spp. }\end{array}$ & $\mathrm{NO}$ & Hap_G & $\begin{array}{l}\text { Auxis thazard } \\
\text { (6), A. rochei (7), } \\
\text { Euthynnus } \\
\text { affinis (1) }\end{array}$ & & YES & $\mathrm{NO}$ \\
\hline 13 & $\mathrm{~T} 5$ & 紅鷹牌 & 活寶食品 & Taiwan & $\begin{array}{l}\text { 細鷹牌海 } \\
\text { 底䌖(魚罐) }\end{array}$ & & 鮁魚 & $\begin{array}{l}\text { Thunnus } \\
\text { spp. }\end{array}$ & NO & Hap_C & $\begin{array}{l}\text { Katsuwonus } \\
\text { pelamis (7), } \\
\text { Thunnus } \\
\text { albacares (1) }\end{array}$ & & YES & YES \\
\hline 14 & T6 & 紅鷹牌 & 活寶食品 & Taiwan & $\begin{array}{l}\text { 細鷹牌海 } \\
\text { 底嚾水 } \\
\text { 著(魚罐) }\end{array}$ & & 東方菌鰆 & $\begin{array}{l}\text { Oriental } \\
\text { bonito }\end{array}$ & YES & Hap_A & $\begin{array}{l}\text { Sarda orientalis } \\
\text { (3) }\end{array}$ & & $\mathrm{NO}$ & NO \\
\hline 15 & T7 & 紅鷹牌 & 活寶食品 & Taiwan & $\begin{array}{l}\text { 海底濰鮮 } \\
\text { 小味片 } \\
\text { 狀(魚罐) }\end{array}$ & & 鮁魚 (鮁屬) & $\begin{array}{l}\text { Thunnus } \\
\text { spp. } \\
\text { (Thunnus) }\end{array}$ & NO & Hap_F & $\begin{array}{c}\text { Thunnus } \\
\text { tonggol (101), T. } \\
\text { orientalis (4), T. } \\
\text { atlanticus (2), T. } \\
\text { thynnus (4), T. } \\
\text { albacares (14), T. } \\
\text { maccoyii (6), T. } \\
\text { obesus (4), T. } \\
\text { alalunga (1), } \\
\text { Katsuwonus } \\
\text { pelamis (1) }\end{array}$ & T. albacares & $\mathrm{NO}$ & YES \\
\hline 16 & $\mathrm{~T} 8$ & 紅鷹牌 & 活寶食品 & Taiwan & 幼简鮁魚 & $\begin{array}{l}\text { Bamboo } \\
\text { shoots } \\
\text { tuna }\end{array}$ & 正鰹 (鮁族) & $\begin{array}{l}\text { Skipjack } \\
\text { tuna } \\
\text { (Thunnini) }\end{array}$ & NO & Hap_G & $\begin{array}{l}\text { Auxis thazard } \\
\text { (6), A. rochei (7), } \\
\text { Euthynnus } \\
\text { affinis (1) }\end{array}$ & & YES & NO \\
\hline 17 & T9 & 紅鷹牌 & 活寶食品 & Taiwan & $\begin{array}{l}\text { 海底䌖鮮 } \\
\text { の味塊 } \\
\text { 狀(魚罐) }\end{array}$ & & 鮁魚 & $\begin{array}{l}\text { Thunnus } \\
\text { spp. }\end{array}$ & NO & Hap_A & $\begin{array}{c}\text { Sarda orientalis } \\
\text { (3) }\end{array}$ & & YES & NO \\
\hline
\end{tabular}


Table 2. Cont

\begin{tabular}{|c|c|c|c|c|c|c|c|c|c|c|c|c|c|c|}
\hline No. & $\begin{array}{l}\text { Sample } \\
\text { Code }\end{array}$ & Brand & $\begin{array}{l}\text { Manufacturer } \\
\text { or } \\
\text { Importer }\end{array}$ & $\begin{array}{l}\text { Place of } \\
\text { Manufac- } \\
\text { ture }\end{array}$ & $\begin{array}{l}\text { Chinese } \\
\text { Label }\end{array}$ & $\begin{array}{l}\text { English } \\
\text { Label }\end{array}$ & $\begin{array}{l}\text { Declared } \\
\text { Ingredient }\end{array}$ & $\begin{array}{l}\text { English } \\
\text { Transla- } \\
\text { tion of } \\
\text { Ingredient }\end{array}$ & $\begin{array}{l}\text { Inconsistent } \\
\text { Labeling }\end{array}$ & $\begin{array}{c}16 S \text { rRNA } \\
\text { Haplotype } \\
\text { Code }\end{array}$ & $\begin{array}{l}\text { 16S BLAST } \\
\text { (No. of Hits) }\end{array}$ & $\begin{array}{c}\text { CR NJ } \\
\text { Analysis }\end{array}$ & Mislabeled & $\begin{array}{c}\text { True } \\
\text { Canned } \\
\text { Tuna }\end{array}$ \\
\hline 18 & T54 & 紅鷹牌 & 活寶食品 & Taiwan & $\begin{array}{l}\text { 紅鷹牌海 } \\
\text { 底雜鮁魚 } \\
\text { 片 }\end{array}$ & Slices tuna & 正鰹 (鮁族) & $\begin{array}{l}\text { Skipjack } \\
\text { tuna } \\
\text { (Thunnini) }\end{array}$ & NO & Hap_A & $\begin{array}{c}\text { Sarda orientalis } \\
\text { (3) }\end{array}$ & & YES & NO \\
\hline 19 & T55 & 細鷹牌 & 活寶食品 & Taiwan & 洋蒽鮁魚 & Onion tuna & 正鰹 (鮁族) & $\begin{array}{l}\text { Skipjack } \\
\text { tuna } \\
\text { (Thunnini) }\end{array}$ & NO & Hap_G & $\begin{array}{l}\text { Auxis thazard } \\
\text { (6), A. rochei (7), } \\
\text { Euthynnus } \\
\text { affinis (1) }\end{array}$ & & YES & NO \\
\hline 20 & T10 & 台糖 & 台糖 & Taiwan & 香简鮁魚 & $\begin{array}{l}\text { Tuna flakes } \\
\text { with } \\
\text { bamboo } \\
\text { shoots }\end{array}$ & $\begin{array}{c}\text { 鮁魚、鰹 } \\
\text { 魚 }\end{array}$ & $\begin{array}{l}\text { Thunnus } \\
\text { spp., } \\
\text { skipjack } \\
\text { tuna }\end{array}$ & NO & Hap_F & $\begin{array}{c}\text { Thunnus } \\
\text { tonggol (101), T. } \\
\text { orientalis (4), T. } \\
\text { atlanticus (2), T. } \\
\text { thynnus (4), T. } \\
\text { albacares (14), T. } \\
\text { maccoyii (6), T. } \\
\text { obesus (4), T. } \\
\text { alalunga (1), } \\
\text { Katsuwonus } \\
\text { pelamis (1) }\end{array}$ & & NO & YES \\
\hline 21 & T46 & 台糖 & 台糖 & Taiwan & $\begin{array}{c}\text { 台糖三明 } \\
\text { 治鮁魚(油 } \\
\text { 漬) }\end{array}$ & $\begin{array}{l}\text { Tuna flakes } \\
\text { in oil }\end{array}$ & 鮁鰹魚類 & $\begin{array}{l}\text { Thunnus } \\
\text { spp., } \\
\text { skipjack } \\
\text { tuna }\end{array}$ & NO & Hap_H & $\begin{array}{l}\text { Thunnus } \\
\text { tonggol (1), T. } \\
\text { obesus (1) }\end{array}$ & & NO & YES \\
\hline 22 & T61 & 台糖 & 台糖 & Taiwan & $\begin{array}{l}\text { 台糖鮁魚 } \\
\text { 片(油漬) }\end{array}$ & $\begin{array}{l}\text { Tuna flakes } \\
\text { in oil }\end{array}$ & $\begin{array}{c}\text { 鮁魚、鰹 } \\
\text { 魚 }\end{array}$ & $\begin{array}{l}\text { Thunnus } \\
\text { spp., } \\
\text { skipjack } \\
\text { tuna }\end{array}$ & NO & Hap_F & $\begin{array}{c}\text { Thunnus } \\
\text { tonggol (101), T. } \\
\text { orientalis (4), T. } \\
\text { atlanticus (2), T. } \\
\text { thynnus (4), T. } \\
\text { albacares (14), T. } \\
\text { maccoyii (6), T. } \\
\text { obesus (4), T. } \\
\text { alalunga (1), } \\
\text { Katsuwonus } \\
\text { pelamis (1) }\end{array}$ & & NO & YES \\
\hline
\end{tabular}


Table 2. Cont

\begin{tabular}{|c|c|c|c|c|c|c|c|c|c|c|c|c|c|c|}
\hline No. & $\begin{array}{l}\text { Sample } \\
\text { Code }\end{array}$ & Brand & $\begin{array}{c}\text { Manufacturer } \\
\text { or } \\
\text { Importer }\end{array}$ & $\begin{array}{l}\text { Place of } \\
\text { Manufac- } \\
\text { ture }\end{array}$ & $\begin{array}{l}\text { Chinese } \\
\text { Label }\end{array}$ & $\begin{array}{l}\text { English } \\
\text { Label }\end{array}$ & $\begin{array}{l}\text { Declared } \\
\text { Ingredient }\end{array}$ & $\begin{array}{c}\text { English } \\
\text { Transla- } \\
\text { tion of } \\
\text { Ingredient }\end{array}$ & $\begin{array}{l}\text { Inconsistent } \\
\text { Labeling }\end{array}$ & $\begin{array}{l}\text { 16S rRNA } \\
\text { Haplotype } \\
\text { Code }\end{array}$ & $\begin{array}{l}\text { 16S BLAST } \\
\text { (No. of Hits) }\end{array}$ & $\begin{array}{c}\text { CR NJ } \\
\text { Analysis }\end{array}$ & Mislabeled & $\begin{array}{c}\text { True } \\
\text { Canned } \\
\text { Tuna }\end{array}$ \\
\hline 23 & T11 & 新東陽 & 新東陽 & Taiwan & $\begin{array}{l}\text { 新東陽水 } \\
\text { 煮鮁魚片 }\end{array}$ & & $\begin{array}{c}\text { 鯆魚、鰹 } \\
\text { 魚 }\end{array}$ & $\begin{array}{l}\text { Thunnus } \\
\text { spp., } \\
\text { skipjack } \\
\text { tuna }\end{array}$ & NO & Hap_G & $\begin{array}{l}\text { Auxis thazard } \\
\text { (6), A. rochei (7), } \\
\text { Euthynnus } \\
\text { affinis (1) }\end{array}$ & & YES & NO \\
\hline 24 & T12 & 愛之味 & 愛之味 & Taiwan & $\begin{array}{l}\text { 愛之味鮁 } \\
\text { 魚片 }\end{array}$ & Tuna slice & 鮁魚 & $\begin{array}{l}\text { Thunnus } \\
\text { spp. }\end{array}$ & $\mathrm{NO}$ & Hap_F & $\begin{array}{c}\text { Thunnus } \\
\text { tonggol (101), T. } \\
\text { orientalis (4), T. } \\
\text { atlanticus (2), T. } \\
\text { thynnus (4),T. } \\
\text { albacares (14),T. } \\
\text { maccoyii (6), T. } \\
\text { obesus (4), T. } \\
\text { alalunga (1), } \\
\text { Katsuwonus } \\
\text { pelamis (1) }\end{array}$ & & $\mathrm{NO}$ & YES \\
\hline 25 & $\mathrm{~T} 45$ & 愛之味 & 愛之味 & Thailand & $\begin{array}{c}\text { 珍寶三明 } \\
\text { 治鮁魚 }\end{array}$ & $\begin{array}{l}\text { AGV deli } \\
\text { style tuna }\end{array}$ & 鮁魚 & $\begin{array}{l}\text { Thunnus } \\
\text { spp. }\end{array}$ & NO & Hap_F & $\begin{array}{c}\text { Thunnus } \\
\text { tonggol (101), T. } \\
\text { orientalis (4), T. } \\
\text { atlanticus (2), T. } \\
\text { thynnus (4), T. } \\
\text { albacares (14),T. } \\
\text { maccoyii (6), T. } \\
\text { obesus (4), T. } \\
\text { alalunga (1), } \\
\text { Katsuwonus } \\
\text { pelamis (1) }\end{array}$ & & NO & YES \\
\hline 26 & T13 & 老船長 & $\begin{array}{c}\text { 金春勝食 } \\
\text { 品 }\end{array}$ & Taiwan & $\begin{array}{c}\text { 老船長特 } \\
\text { 製鮁魚(煙 } \\
\text { 仔虎) }\end{array}$ & Tuna fish & 煙仔虎 & $\begin{array}{c}\text { Skipjact } \\
\text { tuna or } \\
\text { oriental } \\
\text { bonito }\end{array}$ & YES & Hap_A & $\begin{array}{l}\text { Sarda orientalis } \\
\text { (3) }\end{array}$ & & NO & NO \\
\hline
\end{tabular}


Table 2. Cont.

\begin{tabular}{|c|c|c|c|c|c|c|c|c|c|c|c|c|c|c|}
\hline No. & $\begin{array}{l}\text { Sample } \\
\text { Code }\end{array}$ & Brand & $\begin{array}{l}\text { Manufacturer } \\
\text { or } \\
\text { Importer }\end{array}$ & $\begin{array}{l}\text { Place of } \\
\text { Manufac- } \\
\text { ture }\end{array}$ & $\begin{array}{l}\text { Chinese } \\
\text { Label }\end{array}$ & $\begin{array}{l}\text { English } \\
\text { Label }\end{array}$ & $\begin{array}{l}\text { Declared } \\
\text { Ingredient }\end{array}$ & $\begin{array}{c}\text { English } \\
\text { Transla- } \\
\text { tion of } \\
\text { Ingredient }\end{array}$ & $\begin{array}{l}\text { Inconsistent } \\
\text { Labeling }\end{array}$ & $\begin{array}{l}\text { 16S rRNA } \\
\text { Haplotype } \\
\text { Code }\end{array}$ & $\begin{array}{l}\text { 16S BLAST } \\
\text { (No. of Hits) }\end{array}$ & $\begin{array}{c}\text { CR NJ } \\
\text { Analysis }\end{array}$ & Mislabeled & $\begin{array}{c}\text { True } \\
\text { Canned } \\
\text { Tuna }\end{array}$ \\
\hline 27 & T56 & 老船長 & $\begin{array}{c}\text { 金春勝食 } \\
\text { 品 }\end{array}$ & Taiwan & 简仔鮊魚 & $\begin{array}{l}\text { Tuna flakes } \\
\text { with } \\
\text { bamboo } \\
\text { shoots }\end{array}$ & 鮁魚 & $\begin{array}{l}\text { Thunnus } \\
\text { spp. }\end{array}$ & NO & Hap_F & $\begin{array}{c}\text { Thunnus } \\
\text { tonggol (101), T. } \\
\text { orientalis (4), T. } \\
\text { atlanticus (2), T. } \\
\text { thynnus (4), T. } \\
\text { albacares (14), T. } \\
\text { maccoyii (6), T. } \\
\text { obesus (4), T. } \\
\text { alalunga (1), } \\
\text { Katsuwonus } \\
\text { pelamis (1) }\end{array}$ & T. albacares & NO & YES \\
\hline 28 & T14 & 新宜興 & 隆育企業 & Taiwan & 水煮鮊魚 & $\begin{array}{l}\text { Tuna in } \\
\text { brine }\end{array}$ & $\begin{array}{c}\text { 鮁魚、鰹 } \\
\text { 魚 }\end{array}$ & $\begin{array}{l}\text { Thunnus } \\
\text { spp., } \\
\text { skipjack } \\
\text { tuna }\end{array}$ & NO & Hap_H & $\begin{array}{l}\text { Thunnus } \\
\text { tonggol, T. } \\
\text { obesus }\end{array}$ & & $\mathrm{NO}$ & YES \\
\hline 29 & $\mathrm{~T} 47$ & 新宜興 & 隆育企業 & Taiwan & $\begin{array}{l}\text { 新宜興三 } \\
\text { 明治鮊魚 }\end{array}$ & $\begin{array}{c}\text { Tuna } \\
\text { sandwich }\end{array}$ & 鮁鰹魚類 & $\begin{array}{l}\text { Thunnus } \\
\text { spp., } \\
\text { skipjack } \\
\text { tuna }\end{array}$ & NO & Hap_G & $\begin{array}{c}\text { Auxis thazard } \\
\text { (6), A. rochei (7), } \\
\text { Euthynnus } \\
\text { affinis (1) }\end{array}$ & & YES & NO \\
\hline 30 & T58 & 新宜興 & 隆育企業 & Taiwan & $\begin{array}{l}\text { 新宜興原 } \\
\text { 味鮹魚片 }\end{array}$ & Tuna slice & $\begin{array}{c}\text { 鮁魚、鰹 } \\
\text { 魚 }\end{array}$ & $\begin{array}{l}\text { Thunnus } \\
\text { spp., } \\
\text { skipjack } \\
\text { tuna }\end{array}$ & NO & Hap_G & $\begin{array}{c}\text { Auxis thazard } \\
\text { (6), A. rochei (7), } \\
\text { Euthynnus } \\
\text { affinis (1) }\end{array}$ & & YES & NO \\
\hline 31 & T15 & $\begin{array}{l}\text { Viridis } \\
\text { Vivus }\end{array}$ & 隆育企業 & Taiwan & V V 鮁魚片 & Tuna slice & $\begin{array}{c}\text { 鮁魚、鰹 } \\
\text { 魚 }\end{array}$ & $\begin{array}{l}\text { Thunnus } \\
\text { spp., } \\
\text { skipjack } \\
\text { tuna }\end{array}$ & NO & Hap_G & $\begin{array}{c}\text { Auxis thazard } \\
\text { (6), A. rochei (7), } \\
\text { Euthynnus } \\
\text { affinis (1) }\end{array}$ & & YES & NO \\
\hline 32 & T16 & 同榮 & 同栄害實業 & Taiwan & $\begin{array}{c}\text { 同榮魦撸魚 } \\
\text { 片 }\end{array}$ & $\begin{array}{l}\text { Tuna flake } \\
\text { in oil }\end{array}$ & 煙仔虎 & $\begin{array}{l}\text { Skipjact } \\
\text { tuna or } \\
\text { oriental } \\
\text { bonito }\end{array}$ & YES & Hap_A & $\begin{array}{c}\text { Sarda orientalis } \\
\text { (3) }\end{array}$ & & $\mathrm{NO}$ & NO \\
\hline
\end{tabular}


Table 2. Cont

\begin{tabular}{|c|c|c|c|c|c|c|c|c|c|c|c|c|c|c|}
\hline No. & $\begin{array}{l}\text { Sample } \\
\text { Code }\end{array}$ & Brand & $\begin{array}{c}\text { Manufacturer } \\
\text { or } \\
\text { Importer }\end{array}$ & $\begin{array}{l}\text { Place of } \\
\text { Manufac- } \\
\text { ture }\end{array}$ & $\begin{array}{c}\text { Chinese } \\
\text { Label }\end{array}$ & $\begin{array}{l}\text { English } \\
\text { Label }\end{array}$ & $\begin{array}{l}\text { Declared } \\
\text { Ingredient }\end{array}$ & $\begin{array}{c}\text { English } \\
\text { Transla- } \\
\text { tion of } \\
\text { Ingredient }\end{array}$ & $\begin{array}{l}\text { Inconsistent } \\
\text { Labeling }\end{array}$ & $\begin{array}{l}\text { 16S rRNA } \\
\text { Haplotype } \\
\text { Code }\end{array}$ & $\begin{array}{l}\text { 16S BLAST } \\
\text { (No. of Hits) }\end{array}$ & $\begin{array}{c}\text { CR NJ } \\
\text { Analysis }\end{array}$ & Mislabeled & $\begin{array}{c}\text { True } \\
\text { Canned } \\
\text { Tuna }\end{array}$ \\
\hline 33 & T44 & 同榮 & 同榮頪業 & Vietnam & $\begin{array}{c}\text { 三明治特 } \\
\text { 餐 }\end{array}$ & & 鰹魚 & $\begin{array}{l}\text { Skipjack } \\
\text { tuna }\end{array}$ & $\mathrm{NO}$ & Hap_B & $\begin{array}{l}\text { Euthynnus } \\
\text { affinis (4), E. } \\
\text { lineatus (1) }\end{array}$ & & YES & NO \\
\hline 34 & T17 & 爭鮮 & 爭鮮 & Taiwan & 油漬鮊魚 & $\begin{array}{l}\text { Tuna flakes } \\
\text { in oil }\end{array}$ & $\begin{array}{c}\text { 鮁魚、鰹 } \\
\text { 魚 }\end{array}$ & $\begin{array}{l}\text { Thunnus } \\
\text { spp., } \\
\text { skipjack } \\
\text { tuna }\end{array}$ & $\mathrm{NO}$ & Hap_H & $\begin{array}{l}\text { Thunnus } \\
\text { tonggol (1), T. } \\
\text { obesus (1) }\end{array}$ & & $\mathrm{NO}$ & YES \\
\hline 35 & T19 & 藍海洋 & 旺來興 & Taiwan & $\begin{array}{c}\text { 三明治鮁 } \\
\text { 魚 }\end{array}$ & Tuna in oil & $\begin{array}{c}\text { 鮁魚、鰹 } \\
\text { 魚 }\end{array}$ & $\begin{array}{l}\text { Thunnus } \\
\text { spp., } \\
\text { skipjack } \\
\text { tuna }\end{array}$ & $\mathrm{NO}$ & Hap_G & $\begin{array}{c}\text { Auxis thazard } \\
\text { (6), A. rochei (7), } \\
\text { Euthynnus } \\
\text { affinis (1) }\end{array}$ & & YES & $\mathrm{NO}$ \\
\hline 36 & $\mathrm{~T} 22$ & KY & $\begin{array}{c}\text { 寬元行(進 } \\
\text { 口商) }\end{array}$ & Vietnam & $\begin{array}{c}\text { 三明治鮁 } \\
\text { 魚 }\end{array}$ & $\begin{array}{l}\text { Shredded } \\
\text { light tuna } \\
\text { in oil }\end{array}$ & $\begin{array}{l}\text { 鮁魚、鰹 } \\
\text { 魚 }\end{array}$ & $\begin{array}{l}\text { Thunnus } \\
\text { spp., } \\
\text { skipjack } \\
\text { tuna }\end{array}$ & NO & Hap_F & $\begin{array}{c}\text { Thunnus } \\
\text { tonggol (101), T. } \\
\text { orientalis (4), T. } \\
\text { atlanticus (2), T. } \\
\text { thynnus (4), T. } \\
\text { albacares (14), T. } \\
\text { maccoyii (6), T. } \\
\text { obesus (4), T. } \\
\text { alalunga (1), } \\
\text { Katsuwonus } \\
\text { pelamis (1) }\end{array}$ & & $\mathrm{NO}$ & YES \\
\hline 37 & $\mathrm{~T} 23$ & 大海鮁魚 & 力遠貿易 & Vietnam & 鮁魚罐頭 & & 鮁魚 & $\begin{array}{l}\text { Thunnus } \\
\text { spp. }\end{array}$ & $\mathrm{NO}$ & Hap_F & $\begin{array}{c}\text { Thunnus } \\
\text { tonggol (101), T. } \\
\text { orientalis (4), T. } \\
\text { atlanticus (2), T. } \\
\text { thynnus (4), T. } \\
\text { albacares (14), T. } \\
\text { maccoyii (6), T. } \\
\text { obesus (4), T. } \\
\text { alalunga (1), } \\
\text { Katsuwonus } \\
\text { pelamis (1) }\end{array}$ & & $\mathrm{NO}$ & YES \\
\hline
\end{tabular}


Table 2. Cont

\begin{tabular}{|c|c|c|c|c|c|c|c|c|c|c|c|c|c|c|}
\hline No. & $\begin{array}{l}\text { Sample } \\
\text { Code }\end{array}$ & Brand & $\begin{array}{l}\text { Manufacturer } \\
\text { or } \\
\text { Importer }\end{array}$ & $\begin{array}{l}\text { Place of } \\
\text { Manufac- } \\
\text { ture }\end{array}$ & $\begin{array}{c}\text { Chinese } \\
\text { Label }\end{array}$ & $\begin{array}{l}\text { English } \\
\text { Label }\end{array}$ & $\begin{array}{l}\text { Declared } \\
\text { Ingredient }\end{array}$ & $\begin{array}{c}\text { English } \\
\text { Transla- } \\
\text { tion of } \\
\text { Ingredient }\end{array}$ & $\begin{array}{l}\text { Inconsistent } \\
\text { Labeling }\end{array}$ & $\begin{array}{l}16 S \text { rRNA } \\
\text { Haplotype } \\
\text { Code }\end{array}$ & $\begin{array}{l}\text { 16S BLAST } \\
\text { (No. of Hits) }\end{array}$ & $\begin{array}{c}\text { CR NJ } \\
\text { Analysis }\end{array}$ & Mislabeled & $\begin{array}{c}\text { True } \\
\text { Canned } \\
\text { Tuna }\end{array}$ \\
\hline 38 & $\mathrm{~T} 24$ & 紅龍 & 碁富食品 & Thailand & $\begin{array}{l}\text { 細龍嚴選 } \\
\text { 三明治鮁 } \\
\quad \text { 魚 }\end{array}$ & & 鮁魚 & $\begin{array}{l}\text { Thunnus } \\
\text { spp. }\end{array}$ & NO & Hap_C & $\begin{array}{c}\text { Katsuwonus } \\
\text { pelamis (7), } \\
\text { Thunnus } \\
\text { albacares (1) }\end{array}$ & & YES & YES \\
\hline 39 & $\mathrm{~T} 25$ & 金熊 & $\begin{array}{c}\text { 洋鼎(進口 } \\
\text { 商) }\end{array}$ & Indonesia & $\begin{array}{l}\text { 金熊三明 } \\
\text { 治鮁魚 }\end{array}$ & & 鮁魚 & $\begin{array}{l}\text { Thunnus } \\
\text { spp. }\end{array}$ & NO & Hap_C & $\begin{array}{c}\text { Katsuwonus } \\
\text { pelamis (7), } \\
\text { Thunnus } \\
\text { albacares (1) }\end{array}$ & & YES & YES \\
\hline 40 & $\mathrm{~T} 27$ & MACORO & $\begin{array}{c}\text { 寬元行(進 } \\
\text { 口商) }\end{array}$ & Vietnam & $\begin{array}{c}\text { 每口樂片 } \\
\text { 狀三明治 } \\
\text { 鮁魚 }\end{array}$ & $\begin{array}{c}\text { Tuna flake } \\
\text { in oil }\end{array}$ & $\begin{array}{c}\text { 鮁魚、鰹 } \\
\text { 魚 }\end{array}$ & $\begin{array}{l}\text { Thunnus } \\
\text { spp., } \\
\text { skipjack } \\
\text { tuna }\end{array}$ & NO & Hap_H & $\begin{array}{c}\text { Thunnus } \\
\text { tonggol (1), T. } \\
\text { obesus (1) }\end{array}$ & & $\mathrm{NO}$ & YES \\
\hline 41 & $\mathrm{~T} 28$ & 南海洋 & 力遠貿易 & Taiwan & $\begin{array}{c}\text { 油漬鮁 } \\
\text { 魚(煙仔虎) }\end{array}$ & & 煙仔虎 & $\begin{array}{c}\text { Skipjact } \\
\text { tuna or } \\
\text { oriental } \\
\text { bonito }\end{array}$ & YES & Hap_A & $\begin{array}{c}\text { Sarda orientalis } \\
\text { (3) }\end{array}$ & & NO & NO \\
\hline 43 & T30 & 慶全 & $\begin{array}{c}\text { 老三林食 } \\
\text { 品 }\end{array}$ & Taiwan & $\begin{array}{c}\text { 慶全油漬 } \\
\text { 鮁魚 }\end{array}$ & & 鮁鰹魚肉 & $\begin{array}{l}\text { Thunnus } \\
\text { spp., } \\
\text { skipjack } \\
\text { tuna }\end{array}$ & NO & Hap_A & $\begin{array}{c}\text { Sarda orientalis } \\
\text { (3) }\end{array}$ & & YES & NO \\
\hline
\end{tabular}


Table 2. Cont

\begin{tabular}{|c|c|c|c|c|c|c|c|c|c|c|c|c|c|c|}
\hline No. & $\begin{array}{l}\text { Sample } \\
\text { Code }\end{array}$ & Brand & $\begin{array}{c}\text { Manufacturer } \\
\text { or } \\
\text { Importer }\end{array}$ & $\begin{array}{l}\text { Place of } \\
\text { Manufac- } \\
\text { ture }\end{array}$ & $\begin{array}{c}\text { Chinese } \\
\text { Label }\end{array}$ & $\begin{array}{l}\text { English } \\
\text { Label }\end{array}$ & $\begin{array}{l}\text { Declared } \\
\text { Ingredient }\end{array}$ & $\begin{array}{c}\text { English } \\
\text { Transla- } \\
\text { tion of } \\
\text { Ingredient }\end{array}$ & $\begin{array}{l}\text { Inconsistent } \\
\text { Labeling }\end{array}$ & $\begin{array}{l}\text { 16S rRNA } \\
\text { Haplotype } \\
\text { Code }\end{array}$ & $\begin{array}{l}\text { 16S BLAST } \\
\text { (No. of Hits) }\end{array}$ & $\begin{array}{c}\text { CR NJ } \\
\text { Analysis }\end{array}$ & Mislabeled & $\begin{array}{c}\text { True } \\
\text { Canned } \\
\text { Tuna }\end{array}$ \\
\hline 44 & $\mathrm{~T} 40$ & 老三林 & $\begin{array}{c}\text { 老三林食 } \\
\text { 品 }\end{array}$ & Taiwan & $\begin{array}{c}\text { 油漬魚(煙 } \\
\text { 付虎) }\end{array}$ & & 煙仔虎 & $\begin{array}{c}\text { Skipjact } \\
\text { tuna or } \\
\text { oriental } \\
\text { bonito }\end{array}$ & YES & Hap_A & $\begin{array}{l}\text { Sarda orientalis } \\
\text { (3) }\end{array}$ & & $\mathrm{NO}$ & NO \\
\hline 45 & T31 & 三乃 & 三乃 & Taiwan & $\begin{array}{l}\text { 三乃油漬 } \\
\text { 鮕魚片肉 }\end{array}$ & $\begin{array}{l}\text { light meat } \\
\text { tuna }\end{array}$ & 鮁魚 & $\begin{array}{l}\text { Thunnus } \\
\text { spp. }\end{array}$ & NO & Hap_G & $\begin{array}{l}\text { Auxis thazard } \\
\text { (6), A. rochei (7), } \\
\text { Euthynnus } \\
\text { affinis (1) }\end{array}$ & & YES & NO \\
\hline 46 & T32 & 雄雞標 & 駿伸企業* & Thailand & $\begin{array}{c}\text { 雄䌖標特 } \\
\text { 級初篗檄 } \\
\text { 欖油浸鮁 } \\
\text { 魚片 } \\
\text { Omega3 }\end{array}$ & $\begin{array}{c}\text { Tuna } \\
\text { omega3 in } \\
\text { extra } \\
\text { virgin } \\
\text { olive oil }\end{array}$ & 精選鮁魚 & $\begin{array}{l}\text { Thunnus } \\
\text { spp. }\end{array}$ & NO & Hap_F & $\begin{array}{c}\text { Thunnus } \\
\text { tonggol (101), T. } \\
\text { orientalis (4), T. } \\
\text { atlanticus (2), T. } \\
\text { thynnus (4), T. } \\
\text { albacares (14), T. } \\
\text { maccoyii (6), T. } \\
\text { obesus (4), T. } \\
\text { alalunga (1), } \\
\text { Katsuwonus } \\
\text { pelamis (1) }\end{array}$ & & NO & YES \\
\hline 47 & T33 & 雄雞標 & 駿伸企業* & Thailand & $\begin{array}{c}\text { 雄䌖標初 } \\
\text { 榨檄鲵油 } \\
\text { 鮁魚塊 }\end{array}$ & $\begin{array}{c}\text { Tuna } \\
\text { chunks in } \\
\text { extra } \\
\text { virgin } \\
\text { olive oil }\end{array}$ & 精選鮁魚 & $\begin{array}{l}\text { Thunnus } \\
\text { spp. }\end{array}$ & $\mathrm{NO}$ & Hap_F & $\begin{array}{c}\text { Thunnus } \\
\text { tonggol (101), T. } \\
\text { orientalis (4), T. } \\
\text { atlanticus (2), T. } \\
\text { thynnus (4), T. } \\
\text { albacares (14), T. } \\
\text { maccoyii (6), T. } \\
\text { obesus (4), T. } \\
\text { alalunga (1), } \\
\text { Katsuwonus } \\
\text { pelamis (1) }\end{array}$ & & NO & YES \\
\hline
\end{tabular}


Table 2. Cont.

\begin{tabular}{|c|c|c|c|c|c|c|c|c|c|c|c|c|c|c|}
\hline No. & $\begin{array}{l}\text { Sample } \\
\text { Code }\end{array}$ & Brand & $\begin{array}{l}\text { Manufacturer } \\
\text { or } \\
\text { Importer }\end{array}$ & $\begin{array}{l}\text { Place of } \\
\text { Manufac- } \\
\text { ture }\end{array}$ & $\begin{array}{l}\text { Chinese } \\
\text { Label }\end{array}$ & $\begin{array}{c}\text { English } \\
\text { Label }\end{array}$ & $\begin{array}{l}\text { Declared } \\
\text { Ingredient }\end{array}$ & $\begin{array}{c}\text { English } \\
\text { Transla- } \\
\text { tion of } \\
\text { Ingredient }\end{array}$ & $\begin{array}{l}\text { Inconsistent } \\
\text { Labeling }\end{array}$ & $\begin{array}{l}16 S \text { rRNA } \\
\text { Haplotype } \\
\text { Code }\end{array}$ & $\begin{array}{l}\text { 16S BLAST } \\
\text { (No. of Hits) }\end{array}$ & $\begin{array}{c}\text { CR NJ } \\
\text { Analysis }\end{array}$ & Mislabeled & $\begin{array}{c}\text { True } \\
\text { Canned } \\
\text { Tuna }\end{array}$ \\
\hline 48 & T36 & $\begin{array}{l}\text { 大鯖魚夢 } \\
\text { 工廠 }\end{array}$ & $\begin{array}{c}\text { 山萬海産 } \\
\text { 加工廠 }\end{array}$ & Taiwan & $\begin{array}{c}\text { 黑鮁魚罐 } \\
\text { 頭 }\end{array}$ & $\begin{array}{l}\text { Bluefin } \\
\text { tuna }\end{array}$ & 黑鮁魚肉 & $\begin{array}{l}\text { bluefin } \\
\text { tuna }\end{array}$ & NO & Hap_F & $\begin{array}{c}\text { Thunnus } \\
\text { tonggol (101), T. } \\
\text { orientalis (4), T. } \\
\text { atlanticus (2), T. } \\
\text { thynnus (4), T. } \\
\text { albacares (14), T. } \\
\text { maccoyii (6), T. } \\
\text { obesus (4), T. } \\
\text { alalunga (1), } \\
\text { Katsuwonus } \\
\text { pelamis (1) }\end{array}$ & & $?$ & YES \\
\hline 49 & T37 & 美鷹牌 & $\begin{array}{c}\text { 康律企 } \\
\text { 業(代理商) }\end{array}$ & Thailand & $\begin{array}{l}\text { 美鷹牌鮁 } \\
\text { 魚 }\end{array}$ & & $\begin{array}{c}\text { 鰹魚、鮁 } \\
\text { 魚 }\end{array}$ & $\begin{array}{l}\text { Thunnus } \\
\text { spp., } \\
\text { skipjack } \\
\text { tuna }\end{array}$ & NO & Hap_F & $\begin{array}{c}\text { Thunnus } \\
\text { tonggol (101), T. } \\
\text { orientalis (4), T. } \\
\text { atlanticus (2), T. } \\
\text { thynnus (4), T. } \\
\text { albacares (14), T. } \\
\text { maccoyii (6), T. } \\
\text { obesus (4), T. } \\
\text { alalunga (1), } \\
\text { Katsuwonus } \\
\text { pelamis (1) }\end{array}$ & & NO & YES \\
\hline 50 & T41 & 丸漢堡 & 寶丸食品 & Vietnam & $\begin{array}{l}\text { 鋇丸鮁魚 } \\
\text { 罐頭 }\end{array}$ & & 鮁魚 & $\begin{array}{l}\text { Thunnus } \\
\text { spp. }\end{array}$ & NO & Hap_B & $\begin{array}{l}\text { Euthynnus } \\
\text { affinis (4), E. } \\
\text { lineatus (1) }\end{array}$ & & YES & NO \\
\hline
\end{tabular}


Table 2. Cont

\begin{tabular}{|c|c|c|c|c|c|c|c|c|c|c|c|c|c|c|}
\hline No. & $\begin{array}{l}\text { Sample } \\
\text { Code }\end{array}$ & Brand & $\begin{array}{l}\text { Manufacturer } \\
\text { or } \\
\text { Importer }\end{array}$ & $\begin{array}{l}\text { Place of } \\
\text { Manufac- } \\
\text { ture }\end{array}$ & $\begin{array}{l}\text { Chinese } \\
\text { Label }\end{array}$ & $\begin{array}{l}\text { English } \\
\text { Label }\end{array}$ & $\begin{array}{l}\text { Declared } \\
\text { Ingredient }\end{array}$ & $\begin{array}{c}\text { English } \\
\text { Transla- } \\
\text { tion of } \\
\text { Ingredient }\end{array}$ & $\begin{array}{l}\text { Inconsistent } \\
\text { Labeling }\end{array}$ & $\begin{array}{l}\text { 16S rRNA } \\
\text { Haplotype } \\
\text { Code }\end{array}$ & $\begin{array}{l}\text { 16S BLAST } \\
\text { (No. of Hits) }\end{array}$ & $\begin{array}{c}\text { CR NJ } \\
\text { Analysis }\end{array}$ & Mislabeled & $\begin{array}{c}\text { True } \\
\text { Canned } \\
\text { Tuna }\end{array}$ \\
\hline 51 & $\mathrm{~T} 43$ & 慶祥 & 慶祥食品 & Taiwan & $\begin{array}{l}\text { 慶祥鮁魚 } \\
\text { 罐頭 }\end{array}$ & & 鮊鰹魚類 & $\begin{array}{l}\text { Thunnus } \\
\text { spp., } \\
\text { skipjack } \\
\text { tuna }\end{array}$ & NO & Hap_F & $\begin{array}{c}\text { Thunnus } \\
\text { tonggol (101), T. } \\
\text { orientalis (4), T. } \\
\text { atlanticus (2), T. } \\
\text { thynnus (4), T. } \\
\text { albacares (14), T. } \\
\text { maccoyii (6), T. } \\
\text { obesus (4), T. } \\
\text { alalunga (1), } \\
\text { Katsuwonus } \\
\text { pelamis (1) }\end{array}$ & & NO & YES \\
\hline 52 & $\mathrm{~T} 48$ & $\begin{array}{l}\text { GERRN } \\
\& S A F E\end{array}$ & 永豐生技 & Taiwan & $\begin{array}{c}\text { 橄繯油清 } \\
\text { 鮁魚(東方 } \\
\text { 齒鰆) }\end{array}$ & $\begin{array}{c}\text { Sarda } \\
\text { orientalis } \\
\text { in extra } \\
\text { virgin } \\
\text { olive oil }\end{array}$ & $\begin{array}{l}\text { 鮁魚 (東方 } \\
\text { 圏鰆) }\end{array}$ & $\begin{array}{c}\text { Thunnus } \\
\text { spp. } \\
\text { (oriental } \\
\text { bonito) }\end{array}$ & YES & Hap_A & $\begin{array}{l}\text { Sarda orientalis } \\
\text { (3) }\end{array}$ & & $?$ & NO \\
\hline 53 & $\mathrm{~T} 42$ & $\begin{array}{l}\text { Kirkland } \\
\text { signa- } \\
\text { ture }\end{array}$ & Costco & Fiji & $\begin{array}{l}\text { kirkland } \\
\text { signa- } \\
\text { ture科克蘭 } \\
\text { 鮁魚罐頭 }\end{array}$ & Albacore & $\begin{array}{l}\text { Chinese: } \\
\text { 鮹魚/ } \\
\text { English: } \\
\text { Albacore } \\
\text { tuna }\end{array}$ & $\begin{array}{l}\text { Chinese: } \\
\text { Thunnus } \\
\text { spp./English: } \\
\text { albacore } \\
\text { tuna }\end{array}$ & NO & Hap_D & $\begin{array}{l}\text { Thunnus obesus } \\
\text { (3), T. thynnus } \\
\text { (2), T. albacares } \\
\text { (2), T. alalunga } \\
\text { (3), T. orientalis } \\
\text { (1) }\end{array}$ & & $\mathrm{NO}$ & YES \\
\hline 54 & T26 & マルハ & $\begin{array}{l}\text { マルハニ } \\
\text { チロ株式 } \\
\text { 会社 }\end{array}$ & Japan & $\begin{array}{l}\text { 丸哈鮁魚 } \\
\text { 罐 }\end{array}$ & $\begin{array}{l}\text { Tuna in } \\
\text { soy sauce }\end{array}$ & $\begin{array}{l}\text { Chinese: } \\
\text { 金槍 } \\
\text { 魚/Japanese: } \\
\text { まぐろ }\end{array}$ & $\begin{array}{l}\text { Chinese } \\
\text { and } \\
\text { Japanese: } \\
\text { Thunnus } \\
\text { spp. }\end{array}$ & NO & Hap_F & $\begin{array}{c}\text { Thunnus } \\
\text { tonggol (101), T. } \\
\text { orientalis (4), T. } \\
\text { atlanticus (2), T. } \\
\text { thynnus (4), T. } \\
\text { albacares (14), T. } \\
\text { maccoyii (6), T. } \\
\text { obesus (4), T. } \\
\text { alalunga (1), } \\
\text { Katsuwonus } \\
\text { pelamis (1) }\end{array}$ & & NO & YES \\
\hline
\end{tabular}


Table 2. Cont

\begin{tabular}{|c|c|c|c|c|c|c|c|c|c|c|c|c|c|c|}
\hline No. & $\begin{array}{l}\text { Sample } \\
\text { Code }\end{array}$ & Brand & $\begin{array}{l}\text { Manufacturer } \\
\text { or } \\
\text { Importer }\end{array}$ & $\begin{array}{l}\text { Place of } \\
\text { Manufac- } \\
\text { ture }\end{array}$ & $\begin{array}{c}\text { Chinese } \\
\text { Label }\end{array}$ & $\begin{array}{l}\text { English } \\
\text { Label }\end{array}$ & $\begin{array}{l}\text { Declared } \\
\text { Ingredient }\end{array}$ & $\begin{array}{l}\text { English } \\
\text { Transla- } \\
\text { tion of } \\
\text { Ingredient }\end{array}$ & $\begin{array}{l}\text { Inconsistent } \\
\text { Labeling }\end{array}$ & $\begin{array}{l}\text { 16S rRNA } \\
\text { Haplotype } \\
\text { Code }\end{array}$ & $\begin{array}{l}\text { 16S BLAST } \\
\text { (No. of Hits) }\end{array}$ & $\begin{array}{c}\text { CR NJ } \\
\text { Analysis }\end{array}$ & Mislabeled & $\begin{array}{c}\text { True } \\
\text { Canned } \\
\text { Tuna }\end{array}$ \\
\hline 55 & T50 & 良好生活 & $\begin{array}{c}\text { くらし良 } \\
\text { 好 }\end{array}$ & Thailand & $\begin{array}{c}\text { 生活良好 } \\
\text { 鮁魚䌯( } \\
\text { 入) }\end{array}$ & & $\begin{array}{l}\text { Chinese: } \\
\text { 鮁魚/ } \\
\text { Japanese: } \\
\text { きはだま } \\
\text { ぐろ }\end{array}$ & $\begin{array}{l}\text { Chinese: } \\
\text { Thunnus } \\
\text { spp./Japanese: } \\
\text { yellowfin } \\
\text { tuna }\end{array}$ & NO & Hap_F & $\begin{array}{c}\text { Thunnus } \\
\text { tonggol (101), T. } \\
\text { orientalis (4), T. } \\
\text { atlanticus (2), T. } \\
\text { thynnus (4), T. } \\
\text { albacares (14), T. } \\
\text { maccoyii (6), T. } \\
\text { obesus (4), T. } \\
\text { alalunga (1), } \\
\text { Katsuwonus } \\
\text { pelamis (1) }\end{array}$ & & NO & YES \\
\hline 56 & T51 & $\begin{array}{l}\text { 黃金口 } \\
\text { 福(コウ } \\
\text { フク) }\end{array}$ & $\begin{array}{l}\text { KODANML } \\
\text { GROUP } \\
\text { CO., LTD }\end{array}$ & Thailand & $\begin{array}{c}\text { 黃金口福 } \\
\text { 油三入清 } \\
\text { 鮁魚罐 }\end{array}$ & Light tuna & $\begin{array}{l}\text { Chinese: } \\
\text { 鮁魚/ } \\
\text { Japanese: } \\
\text { まぐろ }\end{array}$ & $\begin{array}{l}\text { Chinese } \\
\text { and } \\
\text { Japanese: } \\
\text { Thunnus } \\
\text { spp. }\end{array}$ & NO & Hap_B & $\begin{array}{l}\text { Euthynnus } \\
\text { affinis (4), E. } \\
\text { lineatus (1) }\end{array}$ & & YES & NO \\
\hline 57 & T59 & HOTEI & $\begin{array}{l}\text { ホテイ } \\
\text { フーズ }\end{array}$ & Thailand & $\begin{array}{l}\text { HOTEI油 } \\
\text { 漬鮁魚罐 } \\
\text { 頭 }\end{array}$ & & $\begin{array}{l}\text { Chinese: } \\
\text { 黃鯺 } \\
\text { 鮁/Japanese: } \\
\text { かつお }\end{array}$ & $\begin{array}{l}\text { Chinese: } \\
\text { yellowfin } \\
\text { tuna/Japanese: } \\
\text { skipjack } \\
\text { tuna }\end{array}$ & $\mathrm{NO}$ & Hap_C & $\begin{array}{l}\text { Katsuwonus } \\
\text { pelamis (7), } \\
\text { Thunnus } \\
\text { albacares (1) }\end{array}$ & & YES & YES \\
\hline 58 & T65 & HOTEi & $\begin{array}{l}\text { ホティ } \\
\text { フーズ }\end{array}$ & Japan & $\begin{array}{c}\text { 豪德水者 } \\
\text { 鮁魚罐 }\end{array}$ & & $\begin{array}{c}\text { Chinese: } \\
\text { 黃鮁 } \\
\text { 魚/Japanese: } \\
\text { きはだま } \\
\text { ぐろ }\end{array}$ & $\begin{array}{l}\text { Chinese } \\
\text { and } \\
\text { Japanese: } \\
\text { yellowfin } \\
\text { tuna }\end{array}$ & NO & Hap_F & $\begin{array}{c}\text { Thunnus } \\
\text { tonggol (101), T. } \\
\text { orientalis (4), T. } \\
\text { atlanticus (2), T. } \\
\text { thynnus (4), T. } \\
\text { albacares (14), T. } \\
\text { maccoyii (6), T. } \\
\text { obesus (4), T. } \\
\text { alalunga (1), } \\
\text { Katsuwonus } \\
\text { pelamis (1) }\end{array}$ & & NO & YES \\
\hline
\end{tabular}


Table 2. Cont.

\begin{tabular}{|c|c|c|c|c|c|c|c|c|c|c|c|c|c|c|}
\hline No. & $\begin{array}{l}\text { Sample } \\
\text { Code }\end{array}$ & Brand & $\begin{array}{l}\text { Manufacturer } \\
\text { or } \\
\text { Importer }\end{array}$ & $\begin{array}{l}\text { Place of } \\
\text { Manufac- } \\
\text { ture }\end{array}$ & $\begin{array}{c}\text { Chinese } \\
\text { Label }\end{array}$ & $\begin{array}{c}\text { English } \\
\text { Label }\end{array}$ & $\begin{array}{l}\text { Declared } \\
\text { Ingredient }\end{array}$ & $\begin{array}{c}\text { English } \\
\text { Transla- } \\
\text { tion of } \\
\text { Ingredient }\end{array}$ & $\begin{array}{l}\text { Inconsistent } \\
\text { Labeling }\end{array}$ & $\begin{array}{l}16 S \text { rRNA } \\
\text { Haplotype } \\
\text { Code }\end{array}$ & $\begin{array}{c}\text { 16S BLAST } \\
\text { (No. of Hits) }\end{array}$ & $\begin{array}{c}\text { CR NJ } \\
\text { Analysis }\end{array}$ & Mislabeled & $\begin{array}{c}\text { True } \\
\text { Canned } \\
\text { Tuna }\end{array}$ \\
\hline 59 & T60 & 今津 & $\begin{array}{c}\text { 今津株式 } \\
\text { 会社 }\end{array}$ & Thailand & $\begin{array}{l}\text { 今津懢魚 } \\
\text { 玉米罐 }\end{array}$ & & $\begin{array}{l}\text { Chinese: } \\
\text { 鰹魚/ } \\
\text { Japanese: } \\
\text { きはだま } \\
\text { ぐろ }\end{array}$ & $\begin{array}{c}\text { Chinese: } \\
\text { skipjack } \\
\text { tuna/ } \\
\text { Japanese: } \\
\text { yellowfin } \\
\text { tuna }\end{array}$ & NO & Hap_F & $\begin{array}{c}\text { Thunnus } \\
\text { tonggol (101), T. } \\
\text { orientalis (4), T. } \\
\text { atlanticus (2), T. } \\
\text { thynnus (4), T. } \\
\text { albacares (14), T. } \\
\text { maccoyii (6), T. } \\
\text { obesus (4), T. } \\
\text { alalunga (1), } \\
\text { Katsuwonus } \\
\text { pelamis (1) }\end{array}$ & & YES & YES \\
\hline 60 & T34 & 極洋 & $\begin{array}{c}\text { 極洋株式 } \\
\text { 會社 }\end{array}$ & Thailand & $\begin{array}{l}\text { 極洋鮁魚 } \\
\text { 罐頭-油漬 }\end{array}$ & & $\begin{array}{c}\text { Chinese: } \\
\text { 鮁魚/ } \\
\text { Japanese: } \\
\text { まぐろ }\end{array}$ & $\begin{array}{l}\text { Chinese } \\
\text { and } \\
\text { Japanese: } \\
\text { Thunnus } \\
\text { spp. }\end{array}$ & NO & Hap_F & $\begin{array}{c}\text { Thunnus } \\
\text { tonggol (101), T. } \\
\text { orientalis (4), T. } \\
\text { atlanticus (2), T. } \\
\text { thynnus (4), T. } \\
\text { albacares (14), T. } \\
\text { maccoyii (6), T. } \\
\text { obesus (4), T. } \\
\text { alalunga (1), } \\
\text { Katsuwonus } \\
\text { pelamis (1) }\end{array}$ & T. albacares & $\mathrm{NO}$ & YES \\
\hline 61 & T35 & 極洋 & $\begin{array}{c}\text { 極洋株式 } \\
\text { 會社 }\end{array}$ & Thailand & $\begin{array}{l}\text { 極洋油漬 } \\
\text { 鰹魚罐 }\end{array}$ & & $\begin{array}{l}\text { Chinese: } \\
\text { 鮁魚/ } \\
\text { Japanese: } \\
\text { まぐろ }\end{array}$ & $\begin{array}{c}\text { Chinese } \\
\text { and } \\
\text { Japanese: } \\
\text { Thunnus } \\
\text { spp. }\end{array}$ & NO & Hap_C & $\begin{array}{l}\text { Katsuwonus } \\
\text { pelamis (7), } \\
\text { Thunnus } \\
\text { albacares (1) }\end{array}$ & & YES & YES \\
\hline
\end{tabular}


Table 2. Cont

\begin{tabular}{|c|c|c|c|c|c|c|c|c|c|c|c|c|c|c|}
\hline No. & $\begin{array}{c}\text { Sample } \\
\text { Code }\end{array}$ & Brand & $\begin{array}{l}\text { Manufacturer } \\
\text { or } \\
\text { Importer }\end{array}$ & $\begin{array}{l}\text { Place of } \\
\text { Manufac- } \\
\text { ture }\end{array}$ & $\begin{array}{l}\text { Chinese } \\
\text { Label }\end{array}$ & $\begin{array}{l}\text { English } \\
\text { Label }\end{array}$ & $\begin{array}{l}\text { Declared } \\
\text { Ingredient }\end{array}$ & $\begin{array}{l}\text { English } \\
\text { Transla- } \\
\text { tion of } \\
\text { Ingredient }\end{array}$ & $\begin{array}{l}\text { Inconsistent } \\
\text { Labeling }\end{array}$ & $\begin{array}{l}\text { 16S rRNA } \\
\text { Haplotype } \\
\text { Code }\end{array}$ & $\begin{array}{c}\text { 16S BLAST } \\
\text { (No. of Hits) }\end{array}$ & $\begin{array}{c}\text { CR NJ } \\
\text { Analysis }\end{array}$ & Mislabeled & $\begin{array}{c}\text { True } \\
\text { Canned } \\
\text { Tuna }\end{array}$ \\
\hline 62 & T38 & 稻葉 & $\begin{array}{c}\text { いなば食 } \\
\text { 品 }\end{array}$ & Thailand & $\begin{array}{l}\text { 稻葉鮁魚 } \\
\text { 鰹魚罐 }\end{array}$ & Light tuna & $\begin{array}{l}\text { Chinese: } \\
\text { 鮁魚、鰹 } \\
\text { 魚/Japanese: } \\
\text { まぐろ }\end{array}$ & $\begin{array}{l}\text { Chinese: } \\
\text { Thunnus } \\
\text { spp. and } \\
\text { skipjack } \\
\text { tuna/ } \\
\text { Japanese: } \\
\text { Thunnus } \\
\text { spp. }\end{array}$ & NO & Hap_C & $\begin{array}{l}\text { Katsuwonus } \\
\text { pelamis (7), } \\
\text { Thunnus } \\
\text { albacares (1) }\end{array}$ & & NO & YES \\
\hline 63 & T39 & 伊藤 & 伊藤食品 & Japan & $\begin{array}{l}\text { 伊藤油清 } \\
\text { 鮹魚(金罐) }\end{array}$ & & $\begin{array}{l}\text { Chinese: } \\
\text { 鮁魚/ } \\
\text { Japanese: } \\
\text { まぐろ }\end{array}$ & $\begin{array}{l}\text { Chinese } \\
\text { and } \\
\text { Japanese: } \\
\text { Thunnus } \\
\text { spp. }\end{array}$ & NO & Hap_F & $\begin{array}{c}\text { Thunnus } \\
\text { tonggol (101), T. } \\
\text { orientalis (4), T. } \\
\text { atlanticus (2), T. } \\
\text { thynnus (4), T. } \\
\text { albacares (14), T. } \\
\text { maccoyii (6), T. } \\
\text { obesus (4), T. } \\
\text { alalunga (1), } \\
\text { Katsuwonus } \\
\text { pelamis (1) }\end{array}$ & & NO & YES \\
\hline 64 & T63 & Hagoromo & $\begin{array}{l}\text { はごろも } \\
\text { フーズ株 } \\
\text { 式会社 }\end{array}$ & Japan & $\begin{array}{l}\text { 一本釗頂 } \\
\text { 級鮁魚罐 }\end{array}$ & & $\begin{array}{l}\text { Chinese: } \\
\text { 鯒魚/ } \\
\text { Japanese: } \\
\text { びんなが } \\
\text { まぐろ }\end{array}$ & $\begin{array}{l}\text { Chinese: } \\
\text { Thunnus } \\
\text { spp./Japanese: } \\
\text { albacore } \\
\text { tuna }\end{array}$ & : & Hap_F & $\begin{array}{c}\text { Thunnus } \\
\text { tonggol (101), T. } \\
\text { orientalis (4), T. } \\
\text { atlanticus (2), T. } \\
\text { thynnus (4), T. } \\
\text { albacares (14), T. } \\
\text { maccoyii (6), T. } \\
\text { obesus (4), } T . \\
\text { alalunga (1), } \\
\text { Katsuwonus } \\
\text { pelamis (1) }\end{array}$ & & NO & YES \\
\hline
\end{tabular}


Table 2. Cont

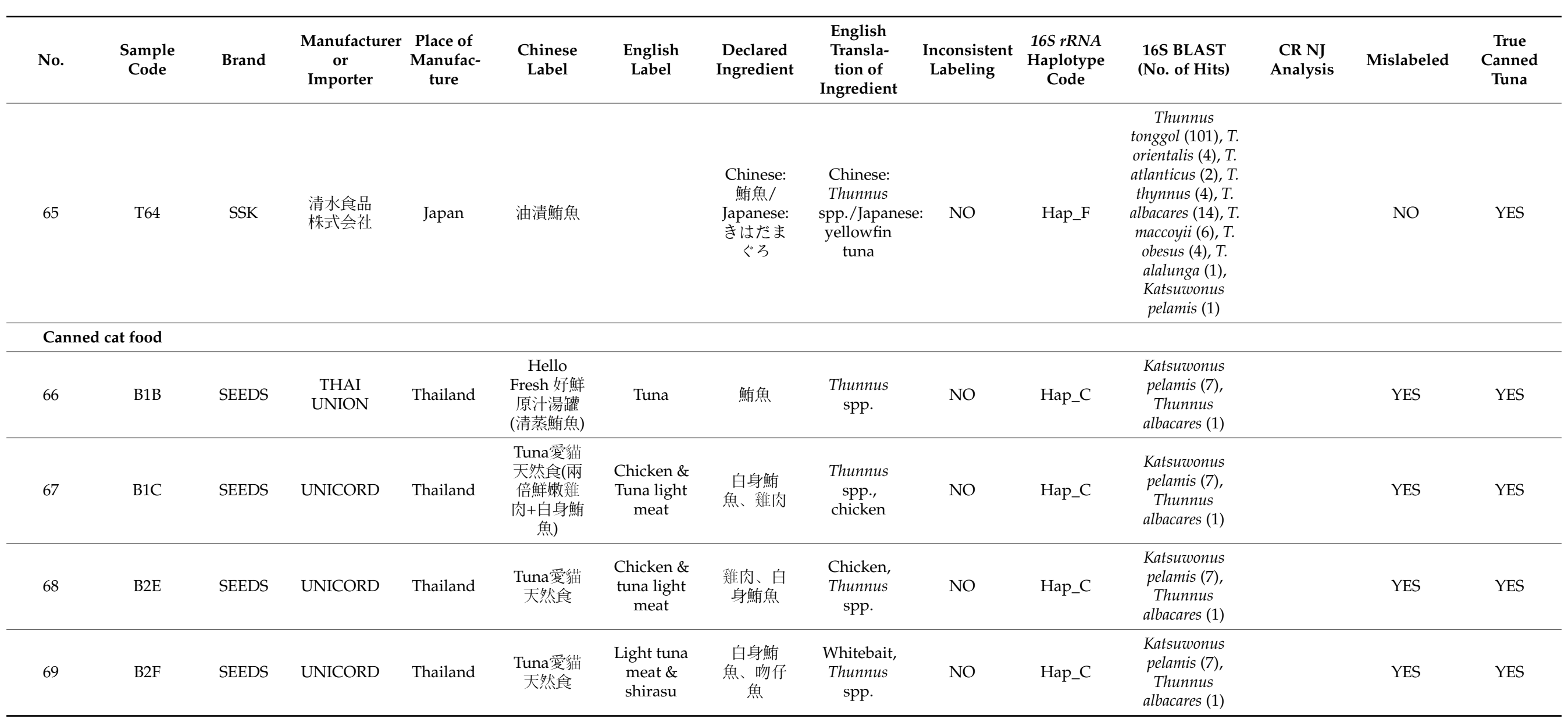


Table 2. Cont

\begin{tabular}{|c|c|c|c|c|c|c|c|c|c|c|c|c|c|c|}
\hline No. & $\begin{array}{l}\text { Sample } \\
\text { Code }\end{array}$ & Brand & $\begin{array}{l}\text { Manufacturer } \\
\text { or } \\
\text { Importer }\end{array}$ & $\begin{array}{l}\text { Place of } \\
\text { Manufac- } \\
\text { ture }\end{array}$ & $\begin{array}{l}\text { Chinese } \\
\text { Label }\end{array}$ & $\begin{array}{c}\text { English } \\
\text { Label }\end{array}$ & $\begin{array}{l}\text { Declared } \\
\text { Ingredient }\end{array}$ & $\begin{array}{c}\text { English } \\
\text { Transla- } \\
\text { tion of } \\
\text { Ingredient }\end{array}$ & $\begin{array}{l}\text { Inconsistent } \\
\text { Labeling }\end{array}$ & $\begin{array}{c}16 S \text { rRNA } \\
\text { Haplotype } \\
\text { Code }\end{array}$ & $\begin{array}{l}\text { 16S BLAST } \\
\text { (No. of Hits) }\end{array}$ & $\begin{array}{c}\text { CR NJ } \\
\text { Analysis }\end{array}$ & Mislabeled & $\begin{array}{c}\text { True } \\
\text { Canned } \\
\text { Tuna }\end{array}$ \\
\hline 70 & $\mathrm{~B} 2 \mathrm{G}$ & SEEDS & $\begin{array}{l}\text { THAI } \\
\text { UNION }\end{array}$ & Thailand & $\begin{array}{l}\text { Bistro Cat } \\
\text { 特級銀貓 } \\
\text { 健康餐罐 }\end{array}$ & $\begin{array}{c}\text { Tuna light } \\
\text { meat }+ \\
\text { shrimp }\end{array}$ & $\begin{array}{c}\text { 白身鮁 } \\
\text { 魚、蝦肉 }\end{array}$ & $\begin{array}{l}\text { Thunnus } \\
\text { spp., } \\
\text { shrimp }\end{array}$ & $\mathrm{NO}$ & Hap_C & $\begin{array}{l}\text { Katsuwonus } \\
\text { pelamis (7), } \\
\text { Thunnus } \\
\text { albacares (1) }\end{array}$ & & YES & YES \\
\hline 71 & B1D & $\begin{array}{c}\text { YAMI亞 } \\
\text { 米 }\end{array}$ & Hi-Q Food & Thailand & $\begin{array}{l}\text { 健寶 鮁魚 } \\
\text { 蟹柳活力 } \\
\text { 餐 } \\
\end{array}$ & & $\begin{array}{c}\text { 鮁魚、蟹 } \\
\text { 柳 }\end{array}$ & $\begin{array}{c}\text { Thunnus } \\
\text { spp., crab } \\
\text { stick }\end{array}$ & $\mathrm{NO}$ & Hap_B & $\begin{array}{l}\text { Euthynnus } \\
\text { affinis (4), E. } \\
\text { lineatus (1) }\end{array}$ & & YES & $\mathrm{NO}$ \\
\hline 72 & B3A & GOEN & $\begin{array}{l}\text { Pataya } \\
\text { Food }\end{array}$ & Thailand & $\begin{array}{c}\text { 御宴湯罐 } \\
\text { 白身鮁 } \\
\text { 魚+雜肉 }\end{array}$ & & $\begin{array}{c}\text { 白身鮁 } \\
\text { 魚、彩肉 }\end{array}$ & $\begin{array}{l}\text { Thunnus } \\
\text { spp., } \\
\text { chicken }\end{array}$ & $\mathrm{NO}$ & Hap_C & $\begin{array}{c}\text { Katsuwonus } \\
\text { pelamis (7), } \\
\text { Thunnus } \\
\text { albacares (1) }\end{array}$ & & YES & YES \\
\hline 73 & B3B & GOEN & $\begin{array}{l}\text { Pataya } \\
\text { Food }\end{array}$ & Thailand & $\begin{array}{c}\text { 御宴湯罐 } \\
\text { 白身鮁 } \\
\text { 魚+鮭魚 }\end{array}$ & & $\begin{array}{l}\text { 白身鮁 } \\
\text { 魚、鮭魚 }\end{array}$ & $\begin{array}{l}\text { Thunnus } \\
\text { spp., } \\
\text { salmon }\end{array}$ & $\mathrm{NO}$ & Hap_C & $\begin{array}{l}\text { Katsuwonus } \\
\text { pelamis (7), } \\
\text { Thunnus } \\
\text { albacares (1) }\end{array}$ & & YES & YES \\
\hline 74 & B3F & 元氣家族 & $\begin{array}{l}\text { Pataya } \\
\text { Food }\end{array}$ & Thailand & $\begin{array}{l}\text { 元氣家族 } \\
\text { 金罐鮁 } \\
\text { 魚+鮦魚 }\end{array}$ & & $\begin{array}{c}\text { 鮁魚、鯛 } \\
\text { 魚 }\end{array}$ & $\begin{array}{c}\text { Thunnus } \\
\text { spp., } \\
\text { snapper }\end{array}$ & $\mathrm{NO}$ & Hap_B & $\begin{array}{l}\text { Euthynnus } \\
\text { affinis (4), E. } \\
\text { lineatus (1) }\end{array}$ & & YES & $\mathrm{NO}$ \\
\hline 75 & B3H & 元氣家族 & $\begin{array}{l}\text { Pataya } \\
\text { Food }\end{array}$ & Thailand & $\begin{array}{l}\text { 元氣家族 } \\
\text { 金罐鮁 } \\
\text { 魚+鮮蝦 }\end{array}$ & & $\begin{array}{l}\text { 鮁魚、鮮 } \\
\text { 蝦 }\end{array}$ & $\begin{array}{l}\text { Thunnus } \\
\text { spp., } \\
\text { shrimp }\end{array}$ & $\mathrm{NO}$ & Hap_B & $\begin{array}{l}\text { Euthynnus } \\
\text { affinis (4), E. } \\
\text { lineatus (1) }\end{array}$ & & YES & $\mathrm{NO}$ \\
\hline 76 & $\mathrm{C} 1 \mathrm{~A}$ & 愛情貴族 & UNICORD & Thailand & $\begin{array}{c}\text { CIH-C08白 } \\
\text { 身鮁魚\&牛 } \\
\text { 肉 }\end{array}$ & & $\begin{array}{c}\text { 白身鮁 } \\
\text { 魚、牛肉 }\end{array}$ & $\begin{array}{l}\text { Thunnus } \\
\text { spp., beef }\end{array}$ & $\mathrm{NO}$ & Hap_E & $\begin{array}{c}\text { Katsuwonus } \\
\text { pelamis (1) }\end{array}$ & & YES & YES \\
\hline 77 & $\mathrm{C} 1 \mathrm{~B}$ & 愛情貴族 & UNICORD & Thailand & $\begin{array}{c}\text { CIH-C02白 } \\
\text { 身鮁魚\&吻 } \\
\text { 仔魚 }\end{array}$ & & $\begin{array}{c}\text { 白身鮁 } \\
\text { 魚、吻仔 } \\
\text { 魚 }\end{array}$ & $\begin{array}{c}\text { Thunnus } \\
\text { spp., } \\
\text { whitebait }\end{array}$ & $\mathrm{NO}$ & Hap_C & $\begin{array}{l}\text { Katsuwonus } \\
\text { pelamis (7), } \\
\text { Thunnus } \\
\text { albacares (1) }\end{array}$ & & YES & YES \\
\hline
\end{tabular}


Table 2. Cont.

\begin{tabular}{|c|c|c|c|c|c|c|c|c|c|c|c|c|c|c|}
\hline No. & $\begin{array}{l}\text { Sample } \\
\text { Code }\end{array}$ & Brand & $\begin{array}{l}\text { Manufacturer } \\
\text { or } \\
\text { Importer }\end{array}$ & $\begin{array}{l}\text { Place of } \\
\text { Manufac- } \\
\text { ture }\end{array}$ & $\begin{array}{l}\text { Chinese } \\
\text { Label }\end{array}$ & $\begin{array}{c}\text { English } \\
\text { Label }\end{array}$ & $\begin{array}{l}\text { Declared } \\
\text { Ingredient }\end{array}$ & $\begin{array}{c}\text { English } \\
\text { Transla- } \\
\text { tion of } \\
\text { Ingredient }\end{array}$ & $\begin{array}{l}\text { Inconsistent } \\
\text { Labeling }\end{array}$ & $\begin{array}{c}16 S \text { rRNA } \\
\text { Haplotype } \\
\text { Code }\end{array}$ & $\begin{array}{l}\text { 16S BLAST } \\
\text { (No. of Hits) }\end{array}$ & $\begin{array}{c}\text { CR NJ } \\
\text { Analysis }\end{array}$ & Mislabeled & $\begin{array}{c}\text { True } \\
\text { Canned } \\
\text { Tuna }\end{array}$ \\
\hline 78 & $\mathrm{C} 2 \mathrm{~B}$ & 每日貓罐 & 泛美力 & Taiwan & $\begin{array}{c}\text { 每日貓 } \\
\text { 罐-鮁魚+蟹 } \\
\text { 味絲湯罐 }\end{array}$ & & $\begin{array}{l}\text { 鮁魚、蟹 } \\
\text { 味綵 }\end{array}$ & $\begin{array}{l}\text { Thunnus } \\
\text { spp., crab } \\
\text { stick }\end{array}$ & $\mathrm{NO}$ & Hap_F & $\begin{array}{c}\text { Thunnus } \\
\text { tonggol (101), T. } \\
\text { orientalis (4), T. } \\
\text { atlanticus (2), T. } \\
\text { thynnus (4), T. } \\
\text { albacares (14), T. } \\
\text { maccoyii (6), T. } \\
\text { obesus (4), T. } \\
\text { alalunga (1), } \\
\text { Katsuwonus } \\
\text { pelamis (1) }\end{array}$ & & NO & YES \\
\hline 79 & $\mathrm{C} 2 \mathrm{C}$ & 每日貓罐 & 泛美力 & Taiwan & $\begin{array}{c}\text { 每日貓 } \\
\text { 罐-鮁魚+巴 } \\
\text { 沙魚湯罐 }\end{array}$ & & $\begin{array}{l}\text { 鮁魚、巴 } \\
\text { 沙魚 }\end{array}$ & $\begin{array}{l}\text { Thunnus } \\
\text { spp., basa } \\
\text { fish }\end{array}$ & $\mathrm{NO}$ & Hap_D & $\begin{array}{l}\text { Thunnus obesus } \\
\text { (3), T. thynnus } \\
\text { (2), T. albacares } \\
\text { (2), T. alalunga } \\
\text { (3), T. orientalis } \\
\text { (1) }\end{array}$ & & $\mathrm{NO}$ & YES \\
\hline
\end{tabular}


Table 2. Cont.

\begin{tabular}{|c|c|c|c|c|c|c|c|c|c|c|c|c|c|c|}
\hline No. & $\begin{array}{l}\text { Sample } \\
\text { Code }\end{array}$ & Brand & $\begin{array}{l}\text { Manufacturer } \\
\text { or } \\
\text { Importer }\end{array}$ & $\begin{array}{l}\text { Place of } \\
\text { Manufac- } \\
\text { ture }\end{array}$ & $\begin{array}{l}\text { Chinese } \\
\text { Label }\end{array}$ & $\begin{array}{l}\text { English } \\
\text { Label }\end{array}$ & $\begin{array}{l}\text { Declared } \\
\text { Ingredient }\end{array}$ & $\begin{array}{l}\text { English } \\
\text { Transla- } \\
\text { tion of } \\
\text { Ingredient }\end{array}$ & $\begin{array}{l}\text { Inconsistent } \\
\text { Labeling }\end{array}$ & $\begin{array}{l}16 S \text { rRNA } \\
\text { Haplotype } \\
\text { Code }\end{array}$ & $\begin{array}{l}\text { 16S BLAST } \\
\text { (No. of Hits) }\end{array}$ & $\begin{array}{c}\text { CR NJ } \\
\text { Analysis }\end{array}$ & Mislabeled & $\begin{array}{c}\text { True } \\
\text { Canned } \\
\text { Tuna }\end{array}$ \\
\hline 81 & $\mathrm{C} 4 \mathrm{C}$ & 鼎食貓罐 & $\begin{array}{l}\text { 沅慶企業 } \\
\text { 有限公司 }\end{array}$ & Taiwan & $\begin{array}{l}\text { 鼎食貓 } \\
\text { 罐\{新鮮鮁 } \\
\text { 魚+櫻花蝦\} }\end{array}$ & & $\begin{array}{l}\text { 鮁魚、櫻 } \\
\text { 花蝦 }\end{array}$ & $\begin{array}{l}\text { Thunnus } \\
\text { spp., } \\
\text { sakura } \\
\text { shrimp }\end{array}$ & NO & Hap_F & $\begin{array}{c}\text { Thunnus } \\
\text { tonggol (101), T. } \\
\text { orientalis (4), T. } \\
\text { atlanticus (2), T. } \\
\text { thynnus (4), T. } \\
\text { albacares (14), T. } \\
\text { maccoyii (6), T. } \\
\text { obesus (4), T. } \\
\text { alalunga (1), } \\
\text { Katsuwonus } \\
\text { pelamis (1) }\end{array}$ & & NO & YES \\
\hline 82 & C5A & 怪獸部落 & $\begin{array}{l}\text { Songkla } \\
\text { Canning }\end{array}$ & Thailand & $\begin{array}{l}\text { 無膠無穀 } \\
\text { 鮮肉煲-鮁 } \\
\text { 魚片湯罐 }\end{array}$ & $\begin{array}{l}\text { Flaked } \\
\text { tuna in } \\
\text { broth }\end{array}$ & 鮁魚 & $\begin{array}{l}\text { Thunnus } \\
\text { spp. }\end{array}$ & NO & Hap_C & $\begin{array}{l}\text { Katsuwonus } \\
\text { pelamis (7), } \\
\text { Thunnus } \\
\text { albacares (1) }\end{array}$ & & YES & YES \\
\hline 83 & D1B & $\begin{array}{l}\text { YAMI亞 } \\
\text { 米 }\end{array}$ & $\begin{array}{l}\text { Hi-Q Food } \\
\text { Products } \\
\text { Co }\end{array}$ & Thailand & $\begin{array}{l}\text { 鮮鮁.䌖肉 } \\
\text { 白金大飺 }\end{array}$ & $\begin{array}{c}\text { YAMI } \\
\text { Platinum }\end{array}$ & 鮁魚白肉 & $\begin{array}{l}\text { Thunnus } \\
\text { spp. }\end{array}$ & NO & Hap_G & $\begin{array}{l}\text { Auxis thazard } \\
\text { (6), A. rochei (7), } \\
\text { Euthynnus } \\
\text { affinis (1) }\end{array}$ & & YES & NO \\
\hline 84 & D1C & $\begin{array}{c}\text { YAMI亞 } \\
\text { 米 }\end{array}$ & $\begin{array}{l}\text { Hi-Q Food } \\
\text { Products } \\
\text { Co }\end{array}$ & Thailand & $\begin{array}{l}\text { 鮮鮁.青花 } \\
\text { 魚.蟹柳白 } \\
\text { 金大餐 }\end{array}$ & $\begin{array}{l}\text { YAMI } \\
\text { Platinum }\end{array}$ & 鮁魚白肉 & $\begin{array}{l}\text { Thunnus } \\
\text { spp. }\end{array}$ & NO & Hap_G & $\begin{array}{l}\text { Auxis thazard } \\
\text { (6), A. rochei (7), } \\
\text { Euthynnus } \\
\text { affinis (1) }\end{array}$ & & YES & NO \\
\hline
\end{tabular}


Table 2. Cont.

\begin{tabular}{|c|c|c|c|c|c|c|c|c|c|c|c|c|c|c|}
\hline No. & $\begin{array}{l}\text { Sample } \\
\text { Code }\end{array}$ & Brand & $\begin{array}{l}\text { Manufacturer } \\
\text { or } \\
\text { Importer }\end{array}$ & $\begin{array}{l}\text { Place of } \\
\text { Manufac- } \\
\text { ture }\end{array}$ & $\begin{array}{l}\text { Chinese } \\
\text { Label }\end{array}$ & $\begin{array}{c}\text { English } \\
\text { Label }\end{array}$ & $\begin{array}{l}\text { Declared } \\
\text { Ingredient }\end{array}$ & $\begin{array}{l}\text { English } \\
\text { Transla- } \\
\text { tion of } \\
\text { Ingredient }\end{array}$ & $\begin{array}{l}\text { Inconsistent } \\
\text { Labeling }\end{array}$ & $\begin{array}{l}\text { 16S rRNA } \\
\text { Haplotype } \\
\text { Code }\end{array}$ & $\begin{array}{l}\text { 16S BLAST } \\
\text { (No. of Hits) }\end{array}$ & $\begin{array}{c}\text { CR NJ } \\
\text { Analysis }\end{array}$ & Mislabeled & $\begin{array}{c}\text { True } \\
\text { Canned } \\
\text { Tuna }\end{array}$ \\
\hline 85 & D2B & TRIL GY & $\begin{array}{l}\text { Real Pet } \\
\text { Food } \\
\text { Company }\end{array}$ & Thailand & $\begin{array}{c}\text { 奇境無穀 } \\
\text { 貓罐野生 } \\
\text { 䰹魚燉䌖 } \\
\text { 湯 }\end{array}$ & & 鮊魚 & $\begin{array}{l}\text { Thunnus } \\
\text { spp. }\end{array}$ & NO & Hap_C & $\begin{array}{l}\text { Katsuwonus } \\
\text { pelamis (7), } \\
\text { Thunnus } \\
\text { albacares (1) }\end{array}$ & & YES & YES \\
\hline 86 & $\mathrm{D} 2 \mathrm{C}$ & $\mathrm{O}^{\prime} \mathrm{KAT}$ & $\begin{array}{l}\text { 黑逗國際 } \\
\text { 有限公司 }\end{array}$ & Thailand & $\begin{array}{l}\text { 美喵人生 } \\
\text { 無穀化毛 } \\
\text { 餐 }\end{array}$ & & 鮁魚 & $\begin{array}{l}\text { Thunnus } \\
\text { spp. }\end{array}$ & NO & Hap_C & $\begin{array}{l}\text { Katsuwonus } \\
\text { pelamis }(7), \\
\text { Thunnus } \\
\text { albacares (1) }\end{array}$ & & YES & YES \\
\hline 87 & $\mathrm{D} 2 \mathrm{G}$ & Rico & $\begin{array}{l}\text { 喬泰寵物 } \\
\text { 用品企羍 } \\
\text { 有限公司 }\end{array}$ & Taiwan & $\begin{array}{l}\text { 岗可-貓用 } \\
\text { 副食鮮湯 } \\
\text { 罐2號(鮊 } \\
\text { 彩䱦䰻魚) }\end{array}$ & & $\begin{array}{l}\text { 鮁魚、熦 } \\
\text { 肉、鰹魚 }\end{array}$ & $\begin{array}{l}\text { Thunnus } \\
\text { spp., } \\
\text { chicken, } \\
\text { skipjack } \\
\text { tuna }\end{array}$ & NO & Hap_F & $\begin{array}{c}\text { Thunnus } \\
\text { tonggol (101), T. } \\
\text { orientalis (4), T. } \\
\text { atlanticus (2), T. } \\
\text { thynnus (4), T. } \\
\text { albacares (14), T. } \\
\text { maccoyii (6), T. } \\
\text { obesus (4), T. } \\
\text { alalunga (1), } \\
\text { Katsuwonus } \\
\text { pelamis (1) }\end{array}$ & T. tonggol & NO & YES \\
\hline 88 & E1E & 樂妙貓 & $\begin{array}{l}\text { サス十株 } \\
\text { 式会社 }\end{array}$ & Japan & $\begin{array}{l}\text { 樂妙貓3㒭- } \\
\text { 鮊.吻 } \\
\quad \text { 瓜 }\end{array}$ & & $\begin{array}{l}\text { Chinese: } \\
\text { 鮊魚、吻 } \\
\text { 仔 } \\
\text { 魚/Japanese: } \\
\text { マグロ、 } \\
\text { しらす }\end{array}$ & $\begin{array}{c}\text { Chinese } \\
\text { and } \\
\text { Japanese: } \\
\text { Thunnus } \\
\text { spp., } \\
\text { whitebait }\end{array}$ & NO & Hap_F & $\begin{array}{c}\text { Thunnus } \\
\text { tonggol (101), T. } \\
\text { orientalis (4), T. } \\
\text { atlanticus (2), T. } \\
\text { thynnus (4), T. } \\
\text { albacares (14),T. } \\
\text { maccoyii (6), T. } \\
\text { obesus (4), T. } \\
\text { alalunga (1), } \\
\text { Katsuwonus } \\
\text { pelamis (1) }\end{array}$ & & NO & YES \\
\hline
\end{tabular}


Table 2. Cont.

\begin{tabular}{|c|c|c|c|c|c|c|c|c|c|c|c|c|c|c|}
\hline No. & $\begin{array}{l}\text { Sample } \\
\text { Code }\end{array}$ & Brand & $\begin{array}{l}\text { Manufacturer } \\
\text { or } \\
\text { Importer }\end{array}$ & $\begin{array}{l}\text { Place of } \\
\text { Manufac- } \\
\text { ture }\end{array}$ & $\begin{array}{l}\text { Chinese } \\
\text { Label }\end{array}$ & $\begin{array}{c}\text { English } \\
\text { Label }\end{array}$ & $\begin{array}{l}\text { Declared } \\
\text { Ingredient }\end{array}$ & $\begin{array}{c}\text { English } \\
\text { Transla- } \\
\text { tion of } \\
\text { Ingredient }\end{array}$ & $\begin{array}{l}\text { Inconsistent } \\
\text { Labeling }\end{array}$ & $\begin{array}{l}16 S \text { rRNA } \\
\text { Haplotype } \\
\text { Code }\end{array}$ & $\begin{array}{l}\text { 16S BLAST } \\
\text { (No. of Hits) }\end{array}$ & $\begin{array}{c}\text { CR NJ } \\
\text { Analysis }\end{array}$ & Mislabeled & $\begin{array}{c}\text { True } \\
\text { Canned } \\
\text { Tuna }\end{array}$ \\
\hline 89 & E2C & 厚肉肉 & $\begin{array}{l}\text { 悠遊國際 } \\
\text { 實業股份 } \\
\text { 有限公司 }\end{array}$ & Taiwan & $\begin{array}{c}\text { T.N.A华遊 } \\
\text { 厚肉肉主 } \\
\text { 食罐-一品 } \\
\text { 鮊魚拚鰉 } \\
\quad \text { 魚 }\end{array}$ & & $\begin{array}{c}\text { 鮁魚、鮭 } \\
\text { 魚 }\end{array}$ & $\begin{array}{l}\text { Thunnus } \\
\text { spp., } \\
\text { salmon }\end{array}$ & NO & Hap_F & $\begin{array}{c}\text { Thunnus } \\
\text { tonggol (101), T. } \\
\text { orientalis (4), T. } \\
\text { atlanticus (2), T. } \\
\text { thynnus (4), T. } \\
\text { albacares (14), T. } \\
\text { maccoyii (6), T. } \\
\text { obesus (4), T. } \\
\text { alalunga (1), } \\
\text { Katsuwonus } \\
\text { pelamis (1) }\end{array}$ & & NO & YES \\
\hline 90 & E2D & 愛喜雅 & $\begin{array}{l}\text { サス十株 } \\
\text { 式会社 }\end{array}$ & Japan & $\begin{array}{l}\text { 燒津43號- } \\
\text { 鮁.彩鮭 }\end{array}$ & & $\begin{array}{l}\text { Chinese: } \\
\text { 鮁魚、䌖: } \\
\text { 令、䱦 } \\
\text { 魚/Japanese: } \\
\text { マグロ、 } \\
\text { 鷄サ+サ } \\
\text { ミ、細鮭 }\end{array}$ & $\begin{array}{l}\text { Chinese } \\
\text { and } \\
\text { Japanese: } \\
\text { Thunnus } \\
\text { spp., } \\
\text { chicken, } \\
\text { salmon }\end{array}$ & NO & Hap_F & $\begin{array}{c}\text { Thunnus } \\
\text { tonggol (101), T. } \\
\text { orientalis (4), } T \text {. } \\
\text { atlanticus (2), } T \text {. } \\
\text { thynnus (4), } T \text {. } \\
\text { albacares (14), T. } \\
\text { maccoyii (6), T. } \\
\text { obesus (4), } T \text {. } \\
\text { alalunga (1), } \\
\text { Katsuwonus } \\
\text { pelamis (1) }\end{array}$ & & NO & YES \\
\hline
\end{tabular}




\subsection{Data Analysis}

Edited 16S sequences were first aligned using ClustalW in MEGA11 [49], and then the haplotypes were determined in DnaSP 6. Species identity for each $16 S$ haplotype was achieved by comparing them (by BLAST) to reference sequences in the NCBI GenBank database. Following the approach of both Armani et al. [50] and Horreo et al. [51], only matches displaying full sequence coverage and $100 \%$ similarity, and with unambiguous species-level scientific names, were considered positive fish identifications. If more than one fish species was shown as a positive match, all of them were considered potential candidates (Table 2).

All CR sequences used in the study of Mitchell and Hellberg (2016) were downloaded to serve as reference sequences, and then our $\mathrm{CR}$ fragments and reference sequences were aligned in ClustalW. A neighbor-joining (NJ) analysis was then conducted based on Kimura two-parameter (K2P) distances and $1 \times 10^{3}$ bootstrapping replicates in MEGA11 [49]. According to the phylogenetic species concept [52], monophyly is a prerequisite for species recognition, so our specimens were authenticated based on the reference species with which they clustered and formed a monophyletic group (with high statistical support, i.e., bootstrapping value $\geq 70$ ) in the NJ phenogram.

\subsection{Comparison of Analytical Results and Product Labels}

We compared the molecular identification of each sample to the ingredient list of the sampled cans. Since a Taiwanese government-approved standard for common names of fishes does not exist, the English names of labeled Chinese names were ascertained from the fish database of Taiwan (https: / / fishdb.sinica.edu.tw / (accessed on 26 October 2021)). Although the Chinese symbols 鰹魚could broadly refer to any species from the genera Auxis (in Chinese: 花鰹屬), Euthynnus (in Chinese: 巴鰹屬), and Katsuwonus (in Chinese: 正 鰹屬), skipjack tuna is the only species generally termed 鰹魚 and that can be used legally in Taiwan to make canned tuna (Table 1). Therefore, we assumed that if 鰹魚 appeared on the ingredient list of a canned tuna product, it specifically represented skipjack tuna. Many of the imported products displayed labeling in Chinese and the language of source, but in those cases we exclusively relied on the Chinese label since Chinese is the only official language in Taiwan.

A sample was judged as displaying inconsistent labeling if the fish name in the ingredient list could not be linked unambiguously to a Thunnus species or skipjack tuna. It was then deemed mislabeled if the molecularly authenticated species it contained did not match the ingredient list on the label. Where a vernacular name used in an ingredient list refers to more than one species, a case of mislabeling was assigned when the molecularly authenticated species did not correspond to any fishes bearing that vernacular name. Finally, we determined a product as being true canned tuna if it contained Thunnus species or skipjack tuna.

\section{Results}

We observed inconsistent labeling in 11 of 65 canned tuna products destined for human consumption, but no such problem with cat food products. Inconsistent labeling reflected canned tuna products also claiming to be made from oriental bonito (Sarda orientalis) (in Chinese: 東方䔄鯺) or displaying the ambiguous vernacular name 煙仔虎, which can refer to either skipjack tuna or oriental bonito (Figure 1, Table 2). 

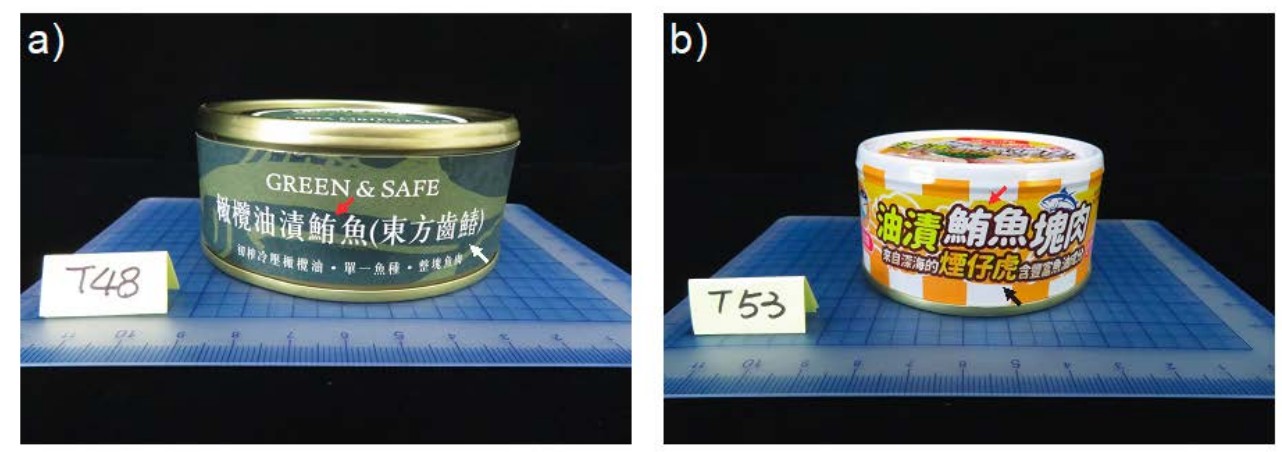

Figure 1. Taiwanese canned tuna products displaying inconsistent labeling. “鮊" (red arrows) in the Chinese labels declares both of these canned tuna products as legally being made from Thunnus fishes or skipjack tuna (Katsuwonus pelamis) (in Chinese: 正鰹). (a) Oriental bonito (Sarda orientalis) (in Chinese: 東方葛鯺) (white arrow) in the label indicates the product contains that species. (b) The Chinese vernacular name 煙仔虎 (black arrow) may represent both oriental bonito and skipjack tuna.

We successfully amplified the $16 \mathrm{~S}$ fragment from all 90 samples, resulting in eight haplotypes (Supplementary Information S2). All haplotypes could be identified to specieslevel by BLAST analysis, but only haplotypes Hap_A and Hap_E specifically relate to oriental bonito and skipjack tuna, respectively. More than one species was identified by BLAST analysis for the remaining six haplotypes, but based on the number of BLAST hits we assume Hap_B represents kawakawa (Euthynnus affinis) (in Chinese: 巴鰹), Hap_C is skipjack tuna, Hap_D and Hap_F are Thunnus species, Hap_H is either longtail tuna (T. tonggol) (in Chinese: 長腰䰹) or bigeye tuna (T. obesus), and Hap_G is either bullet tuna or frigate tuna (Auxis thazard) (in Chinese: 扁花堅).

Our BLAST analysis of $16 \mathrm{~S}$ sequences revealed that 31 of our samples contained Thunnus fishes. However, the success rate of $\mathrm{CR}$ amplification from those samples was quite low $(5 / 31 ; 16 \%)$. The aligned CR dataset (Supplementary Information S3) for NJ analysis is $256 \mathrm{bp}$ in length and contains 47 taxa, including 159 variable sites and 131 parsimonyinformative sites. The NJ analysis of CR sequences supports that samples T1, T7, and T56 are yellowfin tuna, and that sample T34 is longtail tuna, but we could not authenticate sample D2G based on its CR sequence (Figure 2).

Excluding the canned cat food samples that were all accurately labeled, 25 of the remaining 65 canned tuna products were mislabeled and a further three were potential mislabeling cases. Our BLAST analysis confirmed that sample T36 contained Thunnus fish, but did not reveal which species. We found the labeling of sample T48 to be misleading. In Chinese, the symbol "鮊" (for tuna) is never associated with oriental bonito, so it is unreasonable for the symbol for oriental bonito to be placed in parentheses following "鮁 魚" (representing "tuna fish") on the label for this sample. We observed a similar issue for sample T4, since neither skipjack tuna nor oriental bonito can be regarded as a type of "鮊" (Thunnus spp.). Since the ingredient statement on the label fails to clearly indicate which species is contained in the can, it is difficult to judge whether or not these two samples are mislabeled. Notably, many of the products identified as exhibiting inconsistent labeling were also found to be mislabeled. The mislabeling rate of canned products for human consumption was $38 \%(25 / 65)$. Mislabeling was even more pervasive among cat food products, with a rate of $68 \%(17 / 25)$. The main reason for this high mislabeling rate of cat food products is that many claim to contain Thunnus fishes but are in actual fact made from skipjack tuna. The overall mislabeling rate for the 90 tested products of this study is $\sim 47 \%$ (42/90). 


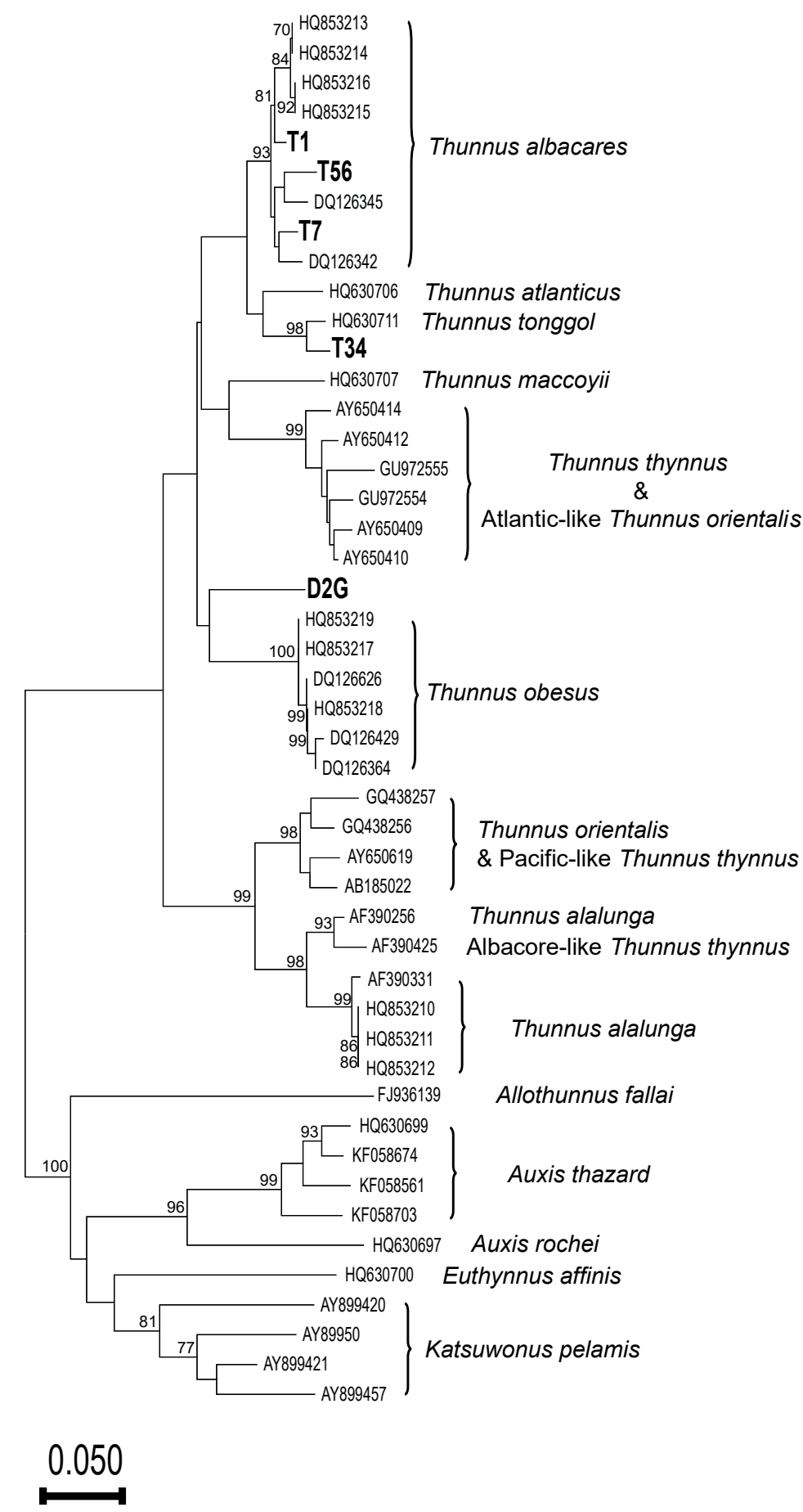

Figure 2. Neighbor-joining (NJ) tree of the K2P model of 47 taxa inferred from $256 \mathrm{bp}$ of mitochondrial control region (CR) sequences with 1000 bootstrapping replicates. Each terminal is labeled with the GenBank accession number or sample code. Bootstrapping values $\geq 70$ are indicated on the respective branches.

Of the 65 human food products we tested, 37 (57\%) legitimately contained either Thunnus fishes or skipjack tuna, and 20 out of 25 cat food products are true canned tuna. Overall, the proportion of true canned tuna products is about $63.33 \%(57 / 90)$ in this study. 


\section{Discussion}

According to Article 28 of the Act Governing Food Safety and Sanitation in Taiwan, public labeling, promotion and advertisement of foods or food additives, cleansers, utensils, containers or packaging designated by the central competent authority shall not be false, exaggerated or misleading. The 11 cases of inconsistent labeling we identified among our 90 samples, which display "鮊" (for tuna) on their labels but also list scombrids other than Thunnus species or skipjack tuna as an ingredient, obviously mislead customers into believing these products contain true canned tuna. For this study, we solely relied on the information on Chinese labeling, but we also noted conflicting information between Chinese and source-language labeling of imported products. For example, the ingredient statement in Japanese of sample T42 clearly declares that it is made from albacore tuna ( $T$. alalunga), but its Chinese label only states that it contains Thunnus fishes (in Chinese: 鮊 魚). Similarly, the Japanese label of sample T59 indicates skipjack tuna as an ingredient (in Japanese: かつお), but its Chinese label specifies yellowfin tuna (in Chinese: 黃鯺鮹) (Table 2). Such conflicting labeling of imported products not only confuses consumers but may also circumvent legal controls.

The "one species-one name" policy is critical to the authentication of fishery products [38]. Clearly, usage of scientific names could enable investigators to easily judge if a product is mislabeled. Under European Union labeling regulations, including the species' scientific name on fishery product labels is mandatory [53]. However, scientific names are not required on Taiwanese fishery products nor are such names familiar to the public. Xiong et al. [54] and Chang et al. [22] advocated the adoption of the Chinese-Latin Dictionary of Fish Names (https: / fishdb.sinica.edu.tw/chi/chinesequer1.php (accessed on 26 October 2021)) as a standard list of fishes in Chinese corresponding to scientific nomenclature. This Dictionary indeed clarifies that the Chinese symbols 東方菌鰆 (in English: oriental bonito) correspond to Sarda orientalis, but it does not include other Chinese vernacular names. Thus, any official "one species-one name" standard should not only contain scientific and Chinese names, but also incorporate vernacular names.

Notably, our success rates for amplifying the two mitochondrial DNA fragments differed considerably-100\% for $16 \mathrm{~S}$, but only $16 \%$ for CR. The canning process is known to damage DNA molecules, with Quinteiro et al. [43] documenting that most DNA segments extracted from canned tuna are $<100 \mathrm{bp}$ in length. Therefore, it is not surprising that amplification of the 85-bp 16S region was more successful than the 236-bp CR fragment (Binominal Generalized Logical Model, $p<0.01$ ).

Apart from haplotypes Hap_A and Hap_C, a single species was not identified by BLAST for the other 16S haplotypes. There are a number of possible reasons for that outcome. First, DNA degradation through the canning process limits molecular authentication based on longer sequences, such as via conventional DNA barcoding. Accordingly, shorter DNA segments must be targeted, but they contain less information and so are less likely to unambiguously assign a specific species [55]. Second, molecular identification based on mitochondrial sequences is very sensitive to gene flow and incomplete lineage sorting $[25,56,57]$. The tribe Thunnus comprises very closely related species, some of which display genetic introgression $[58,59]$. Consequently, though Hap_D, Hap_E, and Hap_H are all clearly form Thunnus fishes, their exact species identity remains unclear. Though conventional DNA barcoding can distinguish Thunnus fishes [60-62], it would be problematic to amplify the $\sim 650 \mathrm{bp}$ barcode from the degraded DNA of canned samples. Third, a reliable database is crucial to accurate DNA-based identification [63]. GenBank does not guarantee that deposited sequences display correct species names. For example, the BLAST result for Hap_C matches multiple sequences for skipjack tuna sequences and one for yellowfin tuna (GenBank accession number: KM055376), implying that accession KM055376 is very likely misidentified. Hence, as highlighted in a number of studies [22,64,65], a reliable and complete DNA reference database for authenticating seafood resources is sorely needed. 
In this study, we found that many canned tuna products in Taiwan are made from oriental bonito, kawakawa, bullet tuna, or frigate tuna instead of legitimate Thunnus fishes or skipjack tuna. Although oriental bonito was never found in canned cat food products, the other three substituted fishes were identified in both human and cat food samples. These same four species have also been reported as illegitimate tuna substitutes in other studies $[44,46,48,50,66,67]$. Though istiophorid fishes have been reported as mislabeled Thunnus products in other studies [46,68], we did not detect them in this study.

Our NJ analysis of CR sequences, including five haplotypes generated in this study, further revealed that both yellowfin tuna and longtail tuna are used in canned tuna products. Yellowfin tuna is one of the commonest canned tunas [5,69], so it is not surprising that three of our five CR haplotypes clustered with yellowfin tuna sequences (sample T34 was identified as longtail tuna, and sample D2G could not be identified to species level). Our difficulties with amplifying the CR region mean that the specific Thunnus composition of canned tuna products in Taiwan remains unclear. Identifying canned tuna products to species level is important because certain Thunnus fishes have higher mercury levels [70], posing a human health risk. Therefore, mitochondrial regions other than CR, such as ATP synthase membrane subunit 8 (ATP8), ATP6, and COIII could be considered [71], or smaller CR fragments could be targeted.

We observed the terms 白身鮁魚 or 鮊魚白肉 commonly in the ingredient statements of our cat food samples (Table 2), reflecting the high mislabeling rate $(17 / 25)$ among cat food products. However, most of the cat food samples (20/25) still represented true canned tuna, albeit not the species that might be expected. To date, there is no official definition for either of these two Chinese terms. They may be translated as "light tuna", which often refers to yellowfin tuna or skipjack tuna, but could actually be any fishes mentioned in the Code of Federal Regulation Title 21 (CFR 161.190) and with flesh color in the Munsell color system $\geq 5.3$ [48]. If those terms were to be officially recognized as translations of light tuna, then the mislabeling rate of cat food we report herein would be much lower (down to 8/25) (Binominal Generalized Logical Model, $p<0.01$ ). Accordingly, we implore the responsible authorities to clearly define the terms for use in canned product labeling.

Although we found that $63.33 \%$ of our samples are true canned tuna, this outcome may not reflect the actual adulteration level of canned tuna products in Taiwan. First, we selected only one small piece of tissue from each can, but the mixing of tuna species in cans has been found in the European market [4]. An assessment of how prevalent the mixing of tuna species is in cans in the Taiwanese market would be needed to determine how close our calculated adulteration level is to the real scenario. Second, we solely sampled major brands, so there are some that remain to be assessed, especially of cat food. Moreover, seasonality in scombrid catch may alter the species composition of adulterated canned tuna products. Thus, more comprehensive and long-term monitoring of the species composition of canned tuna products is needed.

\section{Conclusions}

We report an overall mislabeling rate of $46.67 \%$ among the 90 samples of this study, with $63.33 \%$ of sampled canned products being true canned tuna legitimately made from Thunnus fish or skipjack tuna. In many cases, the labels of the sampled canned tuna products would confuse customers as to what species they contain. Either they contain species such as oriental bonito that do not conform to Taiwanese legislation, or ill-defined terms such as 白身鮊魚 or Chinese vernacular names are used. We assert that a standard list of scientific names and their corresponding Chinese and vernacular names conforming to the "one species-one name" principle, as well as clear definitions of terms for use in canned tuna labeling, is crucial to tackling fish product adulteration. We found that $\sim 37 \%$ of investigated canned tuna products contain illegitimate species. In many cases, the manufacturers have substituted so-called "pseudo-tunas", such as oriental bonito, kawakawa, bullet tuna, and frigate tuna, for legal species, i.e., Thunnus species and skipjack tuna. Our study demonstrates that a pair of primers targeting a short segment $(85 \mathrm{bp})$ of 
$16 \mathrm{~S}$ performs well in amplifying DNA extracted from canned food samples. However, the limited information content provided by this short sequence hampered molecular identification to species level, especially given the close phylogenetic relationships and potential for gene flow among Thunnus species. Moreover, the CR fragment we targeted largely proved uninformative, likely owing to the extreme DNA fragmentation caused by high heat treatment during the canning process. Our previous study of seafood adulteration in conveyor-belt sushi restaurants revealed no case of tuna fraud in such establishments [22], so such adulteration appears to be more common in canned products. A large-scale and long-term monitoring study would help fully establish the extent of canned tuna fraud in the Taiwanese market.

Supplementary Materials: The following are available online at https:/ /www.mdpi.com/article/10 .3390/foods10112655/s1, Supplementary Information S1: The photos of all sampled canned tuna items, Supplementary Information S2: The $16 \mathrm{~S}$ haplotypes, Supplementary Information S3: The aligned CR sequences for constructing $\mathrm{NJ}$ phylogenetic analysis.

Author Contributions: All authors contributed to the study conception and design. Conceptualization, C.-H.C. and Y.-C.W.; methodology, C.-H.C. and Y.-C.W.; software, Y.-T.K. and T.-T.H.; validation, C.-H.C., Y.-T.K. and T.-T.H.; formal analysis, Y.-T.K. and T.-T.H.; investigation, Y.-T.K. and T.-T.H.; resources, Y.-T.K. and T.-T.H.; data curation, Y.-T.K. and T.-T.H.; writing-original draft preparation, C.-H.C.; writing-review and editing, C.-H.C.; visualization, C.-H.C.; supervision, Y.-C.W.; project administration, C.-H.C. and Y.-C.W.; funding acquisition, C.-H.C. All authors have read and agreed to the published version of the manuscript.

Funding: This research was funded by the Ministry of Science and Technology, Taiwan, MOST 109-2621-B-029-006 and 110-2621-B-029-005.

Institutional Review Board Statement: Not applicable.

Informed Consent Statement: Not applicable.

Data Availability Statement: The data presented in this study are available on request from the first author.

Acknowledgments: The authors are grateful to John O'Brien for editing assistance. Lisa, Do-Do, Bagel, Spot, and Jiu-Jiu happily ate the cat food samples after tissue collection.

Conflicts of Interest: The authors declare no conflict of interest.

\section{References}

1. FAO. The State of World Fisheries and Aquaculture 2020; Sustainability in Action; FAO: Rome, Italy, 2020; Available online: http:/ / www.fao.org/state-of-fisheries-aquaculture (accessed on 26 October 2021).

2. Brill, R.W.; Hobday, A.J. Tunas and their fisheries: Safeguarding sustainability in the twenty-first century. Rev. Fish Biol. Fish. 2017, 27, 691-695. [CrossRef]

3. Guillotreau, P.; Squires, D.; Sun, J.; Compeán, G.A. Local, regional and global markets: What drives the tuna fisheries? Rev. Fish Biol. Fish. 2017, 27, 909-929. [CrossRef]

4. Bojolly, D.; Doyen, P.; Fur, B.L.; Christaki, U.; Verrez-Bagnis, V.; Grard, T. Development of a qPCR method for the identification and quantification of two closely related tuna species, bigeye tuna (Thunnus obesus) and yellowfin tuna (Thunnus albacares), in canned tuna. J. Agric. Food Chem. 2017, 65, 913-920. [CrossRef]

5. Mata, W.; Chanmalee, T.; Punyasuk, N.; Thitamadee, S. Simple PCR-RFLP detection method for genus- and species-authentication of four types of tuna used in canned tuna industry. Food Control 2020, 108, 106842. [CrossRef]

6. Ram, J.L.; Ram, M.L.; Baidoun, F.F. Authentication of canned tuna and bonito by sequence and restriction site analysis of polymerase chain reaction products of mitochondrial DNA. J. Agric. Food Chem. 1996, 44, 2460-2467. [CrossRef]

7. 107年度《建構完整食品標示管理體系計畫》一《宣稱鮁魚罐頭之標示説明會》 (in Chinese). Taiwan. Available online: https: // www.ieatpe.org.tw/upload/img-Y29132534-0001 (accessed on 26 October 2021).

8. Standard for Canned Tuna and Bonito CXS 70-1981, Codex Alimentarius FAO-WHO. Available online: https://www.fao.org/ fao-who-codexalimentarius / sh-proxy / es / ?lnk=1\&url=https \%253A \%252F\%252Fworkspace.fao.org \%252Fsites $\% 252$ Fcodex $\%$ 252FStandards\%252FCXS\%2B70-1981\%252FCXS_070e.pdf (accessed on 26 October 2021).

9. Code of Federal Regulations CFR 21. Sec. 161.190. United State Food and Drug Administration; USA. Available online: https:/ / www.accessdata.fda.gov / scripts/cdrh/cfdocs/cfcfr/cfrsearch.cfm?fr=161.190 (accessed on 26 October 2021). 
10. 水産物缶詰及び水産物瓶詰の日本農林規格 (in Japanese) Japan. Available online: https://www.maff.go.jp/j/jas/jas_kikaku/ attach/pdf/kikaku_itiran2-158.pdf (accessed on 26 October 2021).

11. European Regulation (Council Regulation (EEC) No 1536/92). FAO, European Union. 1992. Available online: https: / / www.ecolex.org/details/legislation/council-regulation-eec-no-153692-laying-down-common-marketing-standards-forpreserved-tuna-and-bonito-lex-faoc018868/ (accessed on 26 October 2021).

12. Blanco-Fernandez, C.; Garcia-Vazquez, E.; Machado-Schiaffino, G. Seventeen years analysing mislabelling from DNA barcodes: Towards hake sustainability. Food Control 2020, 123, 107723. [CrossRef]

13. da Silva, C.F.; Daneluz, C.M.; Camacho-Oliveira, R.B.; do Prado, F.D.; Foresti, F.; Rodrigues, C.E., Jr.; Porto-Foresti, F. DNA Barcode reveals mislabelling in the identification of marine fish swimming bladders for commercialization. Forensic Sci. Int. 2019, 299, 41-43. [CrossRef]

14. Delpiani, G.; Delpiani, S.M.; Antoni, M.Y.D.; Ale, M.C.; Fischer, L.; Lucifora, L.O.; de Astarloa, J.M.D. Are we sure we eat what we buy? Fish mislabelling in Buenos Aires province, the largest sea food market in Argentina. Fish Res. 2020, 221, 105373. [CrossRef]

15. Helgoe, J.; Oswald, K.J.; Quattro, J.M. A comprehensive analysis of the mislabeling of Atlantic cod (Gadus morhua) products in Spain. Fish. Res. 2020, 222, 105400. [CrossRef]

16. Kusche, H.; Hanel, R. Consumers of mislabeled tropical fish exhibit increased risks of ciguatera intoxication: A report on substitution patterns in fish imported at Frankfurt Airport, Germany. Food Control 2021, 121, 107647. [CrossRef]

17. Minoudi, S.; Karaiskou, N.; Avgeris, M.; Gkagkavouzis, K.; Tarantilid, P.; Triantafyllidou, D.; Palilis, L.; Avramopoulou, V.; Tsikliras, A.; Barmperis, K.; et al. Seafood mislabeling in Greek market using DNA barcoding. Food Control 2020, $113,107213$. [CrossRef]

18. Pardo, M.Á.; Jiménez, E. DNA barcoding revealing seafood mislabeling in food services from Spain. J. Food Compos. Anal. 2020, 91, 103521. [CrossRef]

19. Prida, V.; Sepúlveda, M.; Quezada-Romegialli, C.; Harrod, C.; Gomez-Uchida, D.; Cid, B.; Canales-Aguirre, C.B. Chilean salmon sushi: Genetics reveals product mislabeling and a lack of reliable information at the point of sale. Foods 2020, 9, 1699. [CrossRef]

20. Staffen, C.F.; Staffen, M.D.; Becker, M.L.; Löfgren, S.E.; Muniz, Y.C.N.; de Freitas, R.H.A.; Marrero, A.R. DNA barcoding reveals the mislabeling of fish in a popular tourist destination in Brazil. Peer] 2017, 5, e4006. [CrossRef] [PubMed]

21. Xiong, X.; Yuan, F.; Huang, M.; Lu, L.; Xiong, X.; Wen, J. DNA barcoding revealed mislabeling and potential health concerns with roasted fish products sold across China. J. Food Prot. 2019, 82, 1200-1209. [CrossRef]

22. Chang, C.-H.; Tsai, M.-L.; Huang, T.-T.; Wang, Y.-C. Authentication of fish species served in conveyor-belt sushi restaurants in Taiwan using DNA barcoding. Food Control 2021, 130, 108264. [CrossRef]

23. Barendse, J.; Roel, A.; Longo, C.; Andriessen, L.; Webster, L.M.I.; Ogden, R.; Neat, F. DNA barcoding validates species labelling of certified seafood. Curr. Biol. 2019, 29, R198-R199. [CrossRef]

24. Chang, C.-H.; Lin, H.-Y.; Ren, Q.; Lin, Y.-S.; Shao, K.-T. DNA barcode identification of fish products in Taiwan: Governmentcommissioned authentication cases. Food Control 2016, 66, 38-43. [CrossRef]

25. Fernandes, T.J.R.; Amaral, J.S.; Mafra, I. DNA barcode markers applied to seafood authentication: An updated review. Crit. Rev. Food Sci. Nutr. 2020, 25, 1-32. [CrossRef]

26. Hellberg, R.S.; Isaacs, R.B.; Hernandez, E.L. Identification of shark species in commercial products using DNA barcoding. Fish. Res. 2019, 210, 81-88. [CrossRef]

27. Liu, C.J.N.; Neo, S.; Rengifo, N.M.; French, I.; Chiang, S.; Ooi, M.; Heng, J.M.; Soon, N.; Yeo, J.Y.; Bungum, H.Z.; et al. Sharks in hot soup: DNA barcoding of shark species traded in Singapore. Fish. Res. 2021, 241, 105994. [CrossRef]

28. Pappalardo, A.M.; Ferrito, V. DNA barcoding species identification unveils mislabeling of processed flatfish products in southern Italy markets. Fish. Res. 2015, 164, 153-158. [CrossRef]

29. Wong, E.H.-K.; Hanner, R.H. DNA barcoding detects market substitution in North American seafood. Food Res. Int. 2008, 41, 828-837. [CrossRef]

30. Ceruso, M.; Mascolo, C.; De Luca, P.; Venuti, I.; Biffali, E.; Ambrosio, R.L.; Smaldone, G.; Sordino, P.; Pepe, T. Dentex dentex Frauds: Establishment of a New DNA Barcoding Marker. Foods 2021, 10, 580. [CrossRef] [PubMed]

31. Paul Greenberg. Four Fish: The Future of the Last Wild Food; Penguin Book: London, UK, 2020.

32. McCluney, J.K.; Anderson, C.M.; Anderson, J.L. The fishery performance indicators for global tuna fisheries. Nat. Commun. 2019, 10, 1641. [CrossRef] [PubMed]

33. Hu, Y.; Huang, S.Y.; Hanner, R.; Levin, J.; Lu, X. Study of fish products in Metro Vancouver using DNA barcoding methods reveals fraudulent labeling. Food Control 2018, 94, 38-47. [CrossRef]

34. Vandamme, S.G.; Griffiths, A.M.; Taylor, S.-A.; Muri, C.D.; Hankard, E.A.; Towne, J.A.; Watson, M.; Mariani, S. Sushi barcoding in the UK: Another kettle of fish. PeerJ 2018, 4, e1891. [CrossRef]

35. Willette, D.A.; Simmonds, S.E.; Cheng, S.H.; Esteves, S.; Kane, T.L.; Nuetzel, H.; Pilaud, N.; Rachmawati, R.; Barber, P.H. Using DNA barcoding to track seafood mislabeling in Los Angeles restaurants. Conserv. Biol. 2017, 31, 1076-1085. [CrossRef] [PubMed]

36. Xing, R.-R.; Hu, R.-R.; Han, J.-X.; Deng, T.-T.; Chen, Y. DNA barcoding and mini-barcoding in authenticating processed animal-derived food: A case study involving the Chinese market. Food Chem. 2020, 309, 125653. [CrossRef] [PubMed]

37. Yang, Q.-Q.; Qian, Z.-X.; Ye, Z.-H.; Zhou, A.-N.; Zhao, X.-X.; Zhang, P.-J.; Liu, G.-F.; Yu, X.-P. Widespread mislabeling of nonnative apple snails (Ampullariidae: Pomacea) as native field snails (Viviparidae: Cipangopaludina) on the Chinese food markets. Aquaculture 2021, 530, 735756. [CrossRef] 
38. Gordoa, A.; Carreras, G.; Sanz, N.; Viñas, J. Tuna species substitution in the spanish commercial chain: A knock-on effect. PLoS ONE 2017, 12, e0170809. [CrossRef] [PubMed]

39. Sotelo, C.G.; Velasco, A.; Perez-Martin, R.I.; Kappel, K.; Schröder, U.; Verrez-Bagnis, V.; Jérôme, M.; Mendes, R.; Silva, H.; Mariani, S.; et al. Tuna labels matter in Europe: Mislabelling rates in different tuna products. PLoS ONE 2018, 13, e0196641. [CrossRef]

40. Ward, R.D.; Hanner, R.; Hebert, P.D.N. The campaign to DNA barcode all fishes, FISH-BOL. J. Fish Biol. 2009, 74, 329-356. [CrossRef]

41. Ceruso, M.; Mascolo, C.; De Luca, P.; Venuti, I.; Smaldone, G.; Biffali, E.; Anastasio, A.; Pepe, T.; Sordino, P. A Rapid Method for the Identification of Fresh and Processed Pagellus erythrinus Species against Frauds. Foods 2020, 9, 1397. [CrossRef] [PubMed]

42. Pollack, S.J.; Kawalek, M.D.; Williams-Hill, D.M.; Hellberg, R.S. Evaluation of DNA barcoding methodologies for the identification of fish species in cooked products. Food Control 2018, 84, 297-304. [CrossRef]

43. Quinteiro, J.; Sotelo, C.G.; Rehbein, H.; Pryde, S.E.; Medina, I.; Pérez-Martín, R.I.; Rey-Méndez, M.; Mackie, I.M. Use of mtDNA direct polymerase chain reaction (PCR) sequencing and PCR-restriction fragment length polymorphism methodologies in species identification of canned tuna. J. Agric. Food Chem. 1998, 46, 1662-1669. [CrossRef]

44. Hwang, C.-C.; Lee, Y.-C.; Huang, Y.-R.; Lin, C.-M.; Shiau, C.-Y.; Hwang, D.-F.; Tsai, Y.-H. Biogenic amines content, histamineforming bacteria and adulteration of bonito in tuna candy products. Food Control 2010, 21, 845-850. [CrossRef]

45. Servusova, E.; Piskata, Z. Identification of selected tuna species in commercial products. Molecules 2021, 26, 1137. [CrossRef]

46. Xiong, X.; Xu, W.; Guo, L.; An, J.; Huang, L.; Qian, H.; Cui, X.; Li, Y.; Cao, M.; Xiong, X.; et al. Development of loop-mediated isothermal amplification (LAMP) assay for rapid screening of skipjack tuna (Katsuwonus pelamis) in processed fish products. J. Food Compos. Anal. 2021, 102, 104038. [CrossRef]

47. Horreo, J.L.; Ardura, A.; Pola, I.G.; Martinez, J.L.; Garcia-Vazquez, E. Universal primers for species authentication of animal foodstuff in a single polymerase chain reaction. J. Sci. Food Agric. 2013, 93, 354-361. [CrossRef] [PubMed]

48. Mitchell, J.K.; Hellberg, R.S. Use of the mitochondrial control region as a potential DNA mini-barcoding target for the identification of canned tuna species. Food Anal. Methods 2016, 9, 2711-2720. [CrossRef]

49. Tamura, K.; Stecher, G.; Kumar, S. MEGA11: Molecular evolutionary genetics analysis version 11. Mol. Biol. Evol. 2021, 38, 3022-3027. [CrossRef] [PubMed]

50. Armani, A.; Tinacci, L.; Xiong, X.; Castigliego, L.; Gianfaldoni, D.; Guidi, A. Fish species identification in canned pet food by BLAST and Forensically Informative Nucleotide Sequencing (FINS) analysis of short fragments of the mitochondrial 16s ribosomal RNA gene (16S rRNA). Food Control 2015, 50, 821-830. [CrossRef]

51. Horreo, J.L.; Fitze, P.S.; Jiménez-Valverde, A.; Noriega, J.A.; Pelaez, M.L. Amplification of 16S rDNA reveals important fish mislabeling in Madrid restaurants. Food Control 2019, 96, 146-150. [CrossRef]

52. Nixon, K.C.; Wheeler, Q.D. An amplification of the phylgenetic species concept. Cladistics 1990, 6, 211-223. [CrossRef]

53. D'Amico, P.; Armani, A.; Gianfaldoni, D.; Guidi, A. New provisions for the labelling of fishery and aquaculture products: Difficulties in the implementation of Regulation (EU) n. 1379/2013. Mar. Policy 2016, 71, 147-156. [CrossRef]

54. Xiong, X.; D'Amico, P.; Guardone, L.; Castigliego, L.; Guidi, A.; Gianfaldoni, D.; Armani, A. The uncertainty of seafood labeling in China: A case study on cod, salmon and tuna. Mar. Policy 2016, 68, 123-135. [CrossRef]

55. Meusnier, I.; Singer, G.A.C.; Landry, J.-F.; Hickey, D.A.; Hebert, P.D.N.; Hajibabaei, M. A universal DNA mini-barcode for biodiversity analysis. BMC Genom. 2008, 9, 214. [CrossRef] [PubMed]

56. Baker, A.J.; Tavares, E.S.; Elbourne, R.F. Countering criticisms of single mitochondrial DNA gene barcoding in birds. Mol. Ecol. Resour. 2009, 9, 257-268. [CrossRef]

57. Weber, A.A.-T.; Stöhr, S.; Chenuil, A. Species delimitation in the presence of strong incomplete lineage sorting and hybridization: Lessons from Ophioderma (Ophiuroidea: Echinodermata). Mol. Phylogenet. Evol. 2019, 131, 138-148. [CrossRef]

58. Bayona-Vásquez, N.J.; Glenn, T.C.; Uribe-Alcocer, M.; Pecoraro, C.; Díaz-Jaimes, P. Complete mitochondrial genome of the yellowfin tuna (Thunnus albacares) and the blackfin tuna (Thunnus atlanticus): Notes on mtDNA introgression and paraphyly on tunas. Conserv. Genet. Resour. 2018, 10, 697-699. [CrossRef]

59. Díaz-Arce, N.; Arrizabalaga, H.; Murua, H.; Irigoien, X.; Rodríguez-Ezpeleta, N. RAD-seq derived genome-wide nuclear markers resolve the phylogeny of tunas. Mol. Phylogenet. Evol. 2016, 102, 202-207. [CrossRef]

60. Abdullah, A.; Rehbein, H. Authentication of raw and processed tuna from Indonesian markets using DNA barcoding, nuclear gene and character-based approach. Eur. Food Res. Technol. 2014, 239, 695-706. [CrossRef]

61. Lowenstein, J.H.; Amato, G.; Kolokotronis, S.-O. The real maccoyii: Identifying tuna sushi with DNA barcodes-contrasting characteristic attributes and genetic distances. PLoS ONE 2009, 4, e7866. [CrossRef]

62. Puncher, G.N.; Arrizabalaga, H.; Alemany, F.; Cariani, A.; Oray, I.K.; Karakulak, F.S.; Basilone, G.; Cuttitta, A.; Mazzola, S.; Tinti, F. Molecular identification of Atlantic bluefin tuna (Thunnus thynnus, Scombridae) larvae and development of a DNA character-based identification key for Mediterranean scombrids. PLoS ONE 2015, 10, e0130407. [CrossRef]

63. Kappel, K.; Schröder, U. Difficulties in DNA barcoding-based authentication of snapper products due to ambiguous nucleotide sequences in public databases. Food Control 2020, 118, 107348. [CrossRef]

64. Mitchell, A.; Rothbart, A.; Frankham, G.; Johnson, R.N.; Neaves, L.E. Could do better! A high school market survey of fish labelling in Sydney, Australia, using DNA barcodes. Peer] 2019, 7, e7138. [CrossRef]

65. Shehata, H.R.; Naaum, A.M.; Garduño, R.A.; Hanner, R. DNA barcoding as a regulatory tool for seafood authentication in Canada. Food Control 2018, 92, 147-153. [CrossRef] 
66. Espiñeira, M.; Gonzalez-Lavín, N.; Vieites, J.M.; Santaclara, F.J. Development of a method for the identification of scombroid and common substitute species in seafood products by FINS. Food Chem. 2009, 117, 698-704. [CrossRef]

67. Lockley, A.K.; Bardsley, R.G. Novel method for the discrimination of tuna (Thunnus thynnus) and bonito (Sarda sarda) DNA. J. Agric. Food Chem. 2020, 48, 4463-4468. [CrossRef] [PubMed]

68. Yao, L.; Lu, J.; Qu, M.; Jiang, Y.; Li, F.; Guo, Y.; Wang, L.; Zhai, Y. Methodology and application of PCR-RFLP for species identification in tuna sashimi. Food Sci. Nutr. 2020, 8, 3138-3146. [CrossRef]

69. Boughattas, F.; Karoui, R. Mid infrared spectroscopy combined with chemometric tools for the identification of canned tuna species in brine. J. Food Compos. Anal. 2021, 96, 103717. [CrossRef]

70. Kumar, G. Mercury concentrations in fresh and canned tuna: A review. Rev. Fish Sci. Aquac. 2018, 26, 111-120. [CrossRef]

71. Amaral, C.R.L.; Maciel, V.; Goldenberg-Barbosa, R.; Silva, D.A.; Amorim, A.; Carvalho, E.F. Tuna fish identification using mtDNA markers. Forensic Sci. Int. Genet. Suppl. Ser. 2017, 6, e471-e473. [CrossRef] 